The original publication is available at http://www.tandf.co.uk/journals/

\title{
Gridded surface wind fields from Metop/ASCAT measurements
}

\author{
Abderrahim Bentamy ${ }^{\mathrm{a},{ }^{*}}$ \& Denis Croize Fillon ${ }^{\mathrm{a}}$ \\ a Laboratoire d'Océanographie Spatiale (LOS), Institut Français pour la Recherche et l'Exploitation de la MER \\ (IFREMER), Plouzané, 29280, France \\ *: Corresponding author : Abderrahim Bentamy, email address : abderrahim.bentamy@ifremer.fr
}

\begin{abstract}
:
This article deals with the calculation and validation of daily surface wind vector fields from wind speed and direction observations derived from Advanced SCATterometer (ASCAT) scatterometer measurements over the global ocean. According to the ASCAT sampling scheme, the objective method allowing for the determination of regular in space and time wind speed and direction fields uses ASCAT observations as well as European Centre for Medium Weather Forecasts (ECMWF) analyses. The latter are considered as external drift for the kriging method and as the temporal interpolation basis for ASCAT retrievals. This study focuses on the investigation of the capability of the method to add valuable wind information to the operational atmospheric analyses and on the quality of the resulting wind fields. The accuracy of the former is determined through comprehensive comparisons with daily winds calculated from moored buoy data. At global and regional scales, comparisons are performed with surface wind patterns derived from the ECMWF analysis and from ECMWF Re-analysis project (ERA-Interim) re-analyses.
\end{abstract}




\section{Introduction}

The precise knowledge of surface wind vectors over global oceans are one of the main requirements of scientific and operational oceanography and climate projects (see, for instance, http://www.myocean.eu.org/ ). Indeed, they induce heat and momentum transfers between the ocean and the atmosphere and are the main driving forces for surface ocean circulation. Surface winds are routinely derived from radars and radiometers onboard satellites. They are available with various spatial and temporal resolutions associated with the instrument characteristics. Generally speaking, they are retrieved over instrument swaths of several hundred-kilometre widths.

A number of studies have considered the problem of producing synoptic wind maps from scatterometer-derived winds using standard statistical procedures. For example, Woiceshyn et al. (1989) interpolated a 15-day record of SEASAT scatterometer winds to a regular grid and achieved favorable results in wave modeling experiments, as compared to using NWP winds. Tang and Liu (1996) produced 12-hourly wind fields on a $1^{\circ}$ latitude-longitude (lat-long) grid, using a successive correction method based on ERS-1 winds and NWP produced winds. Royle et al. (1999) used a Bayesian approach to combine scatterometer winds and NWP winds. Perrie et al (2002) used optimal interpolation $(\mathrm{OI})$ to combine scatterometer and altimeter data with numerical weather prediction (NWP) model wind estimates. Using ERS-1 and ERS-2 scatterometer retrievals, Bentamy et al. $(1996 ; 1998)$ constructed weekly and monthly wind fields over the global oceans with a spatial resolution of $1^{\circ}$ in longitude and latitude. The former were estimated based on the kriging method, which requires the knowledge of the spatial and temporal wind speed, wind stress, and the zonal and meridional component structure functions. Thanks to the QuikSCAT sampling scheme, the objective method has been enhanced for gridded daily, weekly, and monthly global wind field calculations (Bentamy et al, 2002). The related spatial resolution is $0.50^{\circ}$ in longitude and latitude. Gridded QuikSCAT data are available from July 1999 through November 2009. The extension of daily, weekly, and monthly averaged wind field availability is highly requested. To meet such requirements, new gridded wind fields are calculated from the Advanced SCATterometer (ASCAT) measurements on board the Metop-A satellite.

The main purpose of this study is to estimate global wind fields from scatterometer wind observations and to assess their accuracy. The paper describes data sets, the temporal and spatial sampling issues, and the methodology used to generate regular in space and time wind speeds and the related components. The validation of the objective method and of the resulting wind fields as well as the investigation of the spatial and temporal characteristics of ASCAT daily winds are provided .

\section{Data}

ASCAT scatterometer represents the latest implementation of spaceborne microwave wind-measuring scatterometry. Scientific and technical documentation related to ASCAT physical measurements as well as to ASCAT derived products may be found at the EUMETSAT web site

http://www.eumetsat.int/Home/Main/Publications/Technical_and_Scientific_Documenta tion/Technical_Notes/ and at the SAF OSI web site

http://www.knmi.nl/scatterometer/. Metop is in circular orbit (near synchronous orbit) for a period of about 101 minutes, at an inclination of $98.59^{\circ}$ and at a nominal height of $800 \mathrm{~km}$ with a 29-day repeat cycle. ASCAT (Figure 1) has two swaths $550 \mathrm{~km}$ wide, located on each side of the satellite track, separated by $700 \mathrm{~km}$. It operates at $5.3 \mathrm{GHz}$ 
( $C$ band). Its fore-beam and aft-beam antennas point at $45^{\circ}$ and $135^{\circ}$ to each side of the satellite track, respectively. The mid-beam antennas point at $90^{\circ}$. The ASCAT beams measure normalized radar cross sections with vertical polarization, $\sigma^{0}$, which are a dimensionless property of the surface, describing the ratio of the effective echoing area per unit area illuminated. The fore and aft-beams provide backscatter coefficient measurements at incidence angle varying between $34^{\circ}$ and $64^{\circ}$. The midbeams provide $\sigma^{0}$ measurements at incidence angles varying between $25^{\circ}$ and $53^{\circ}$. Backscatter coefficients are provided with two spatial resolutions of $25 \mathrm{~km}$ and $12.5 \mathrm{~km}$ over the global ocean.

All ASCAT products used in this paper correspond to near-realtime data provided by EUMETSAT and by KNMI as the wind component of the Ocean Sea Ice Satellite Application Facility (OSI SAF).

Since 20 March 2007, KNMI processes and makes available surface wind vector derived from ASCAT backscatter coefficients

(http://www.knmi.nl/scatterometer/publications/pdf/ASCAT_Product_Manual.pdf). The ASCAT swath datasets used in this study are referenced as ASCAT level $2 b$ (L2b). ASCAT wind retrievals are provided at WVC of $25 \mathrm{~km}$ by $25 \mathrm{~km}$. There are 42 WVC across the two-scatterometer swaths. Data include wind retrievals as well as backscatter coefficients measured over ocean and several associated fields at each valid WVC. From March 2007 through October 2008, ASCAT winds are considered as 'real winds' and include the atmospheric stratification impact. Since November 2008, ASCAT retrievals are provided as equivalent neutral surface winds.

To determine accuracy, in-situ data derived from buoys are used. They are provided by Météo-France and U.K. MetOffice (MFUK), the National Data Buoy Center (NDBC), the Tropical Atmosphere Ocean Project (TAO), the Pilot Research Moored Array in the Atlantic project (PIRATA), and by the Research Moored Array for African-AsianAustralian Monsoon Analysis and Prediction project (RAMA). They consist of buoys moored off US coasts (NDBC), off European seas (MFUK), and along the Atlantic (PIRATA), Indian (RAMA), and Pacific (TAO) tropical oceans. For purposes of comparison, all buoy winds are adjusted to a height of 10 meters assuming neutral stability.

The NWP surface winds used in this study are derived from the European Centre for Medium Weather Forecasts (ECMWF) operational analysis. They are routinely provided by Météo-France within the Mersea project (http://www.mersea.eu.org/ ). The time resolution of the ECMWF data is four times daily (00h:00, 06h:00, 12h:00 and 18h:00). They are made available on a regular grid of $0.5^{\circ}$ in longitude and latitude. The ECMWF winds are given at $10 \mathrm{~m}$ above sea level in terms of zonal and meridional wind components. Furthermore, the new ERA-Interim reanalysis, which is advanced with respect to ERA-40 (http://www.ecmwf.int/research/era/do/get/era-interim) is also used.

\section{ASCAT Sampling SCHEME}

As expected, the spatial and temporal resolutions of regular wind fields calculated from ASCAT retrievals are highly related to the scatterometer sampling scheme. Figure 2 shows ASCAT wind speed coverage for January $1^{\text {st }}, 2009$ (Figure 2a), and the spatial distribution of scatterometer observation sampling length, number of retrievals located within grid cell of $0.25^{\circ}$ in longitude and latitude, estimated during $1-29$ January 2009 (Figure 2b). . Even though ASCAT provides valuable surface wind observations with 
quite good daily sampling, several oceanic regions are not observed (Figure 2a). Overall, the grid points located north of $40^{\circ} \mathrm{N}$ and south of $40^{\circ} \mathrm{S}$ are observed at least once a day, whereas in the inter-tropical area, the number of ASCAT retrievals falling within each grid point is less than 1 (Figure 2b). Therefore, the calculation of gridded wind fields from ASCAT retrievals, and especially on a daily basis, is a challenging task. Indeed, at several locations, no more than 1 observation a day is expected. The expected impact of such a sampling scheme on the regular wind field calculations is investigated using buoy measurements.

In-situ data are obtained from operational buoy networks involving moorings located off the French and England coasts and maintained by UK Met-Office and/or Météo-France (MFUK hereafter, Figures 3a and 4a) buoys provided by the National Data Buoy Center (NDBC) that are located off and near U.S coasts (Figures $3 b 4 b$ ), buoys of the TAO array located in the equatorial Pacific (Figures $3 \mathrm{c}$ and $4 \mathrm{c}$ ), and buoys of the PIRATA array located in the equatorial Atlantic (Figures $3 d$ and $4 d$ ). Surface winds from buoys are hourly-averaged.

Let $\overline{w_{b}}, \overline{u_{b}}, \overline{v_{b}}$ be the daily-averaged wind speed, zonal, and meridional components calculated from raw and valid buoy data.

$\overline{w_{b s}}, \overline{u_{b s}}, \overline{v_{b s}}$ are daily-averaged wind speed, zonal, and meridional components, respectively, calculated from raw and valid buoy data collocated in space and time with ASCAT WVC retrievals.

The investigation of differences between the two types of averaged buoy data, are used to assess the impact of the ASCAT sampling scheme on daily wind estimations. Figures 3 and 4 show the mean and standard deviation estimates of differences between $\overline{w_{b}}$ and $\overline{w_{b s}}$ calculated during the one-year period. Overall, the biases between the two daily winds are quite low and generally are not significant. The calculation of daily wind speeds from buoy data occurring at ASCAT passes does not yield any systematic bias. The main impact of the ASCAT sampling scheme on daily wind estimation, is clearly found in $\overline{w_{b}}$ and $\overline{w_{b s}}$ difference variability (Figure 4). The latter may reach $2 \mathrm{~ms}^{-1}$ at some locations of the MFUK and NDBC networks. The highest variability values are found at sites where surface winds are highly variable, such as at the Mediterranean Sea buoys (Figure 4a). However, the lowest values are depicted in the tropical areas, associated with low surface wind variability.

Therefore, the calculation of gridded winds from ASCAT retrievals requires the development and use of a method aiming to provide wind vector estimates at regular space and time grids, and to reduce the impact of the scatterometer sampling scheme.

\section{Methodology}

The main aim is to estimate a regular wind field in space and time using ASCAT remotely sensed data. However, regarding the results of the previous section, to better estimate analyses at each grid point, auxiliary information is also used. The latter are derived from the ECMWF operational 10m-wind analysis. The following linear relationship between observations and auxiliary data is assumed:

$$
E(X(x, y, t))=\alpha_{0}+\beta_{1} Y(x, y, t)
$$


$X$ and $Y$ are the target (satellite observation) and auxiliary (ECMWF) wind variables, respectively. $x, y$, and $t$, represent spatial and temporal coordinates. $\alpha_{0}$ and $\beta_{1}$ are coefficients to be estimated. Operator $E$ states the mathematical mean. The above relationship indicates that the auxiliary information provides a mean description of observed wind.

The estimation method is based on kriging with external drift (Wackernagel, 1998).Assume that:

$$
X_{a}=\tilde{X}+\varepsilon
$$

Where $X_{a}$ is the analysis value estimated at a grid point of $\Delta h$ degrees in longitude and latitude over $\Delta t$ hours. For this study $\Delta h$ and $\Delta t$ are $0.50^{\circ}$ and 24 hours, respectively.

$\tilde{X}$ is the true (unknown) surface wind. $\varepsilon$ is the error associated to $X_{a}$

The objective method assumes that the estimator of $\tilde{X}$ at each grid point is provided by:

$\hat{X}_{i}=\frac{1}{\left(t_{b}-t_{a}\right)} \int_{t a}^{t b}\left(\sum_{j=1}^{N} \lambda_{j}\left(X_{o}^{j}\left(x_{j}, y_{j}, t\right)\right) d t\right.$

$\hat{X}_{i}$ stands for the wind estimator at grid point $M_{i}\left(x_{i}, y_{i}\right)$ over the period $\delta t=t_{b}-t_{a}$.

$X_{o}^{j}$ indicates the jth remotely sensed observation vector available over the satellite swath.

$\lambda$ is the weighting vector to be estimated. Its determination, at each grid point, leads to minimize the residual

$$
R=\tilde{X}-\hat{X} \text { with the unbiased constraint } \sum_{j=1}^{N} \lambda_{j}=1
$$

$N$ is the observation number

Using the equations (1) and (3), and the unbiased constraint (eq. 4) the following relationship is drawn:

$$
E\left(\hat{X}_{i}\right)=\alpha_{0}+\beta_{1} Y i
$$

The latter yields to the second constraint:

$$
Y_{i}=\sum_{j=1}^{N} \lambda_{j} Y_{j}
$$

$Y_{i}$ stands for $Y$ values at $\mathrm{M}_{i}$.

The Gauss-Markov theorem indicates that the best estimator in the least-square optimum linear estimator should minimize the residual variance $\operatorname{Var}(R)=E\left((\tilde{X}-\hat{X})^{2}\right)$.

At a given grid point $\mathrm{M} 0=(\mathrm{x} 0, \mathrm{y} 0, \mathrm{t} 0)(\mathrm{x} 0, \mathrm{y} 0$, t0 indicate geographical coordinates and time $)$

$$
\operatorname{Var}\left(R\left(\mathrm{M}_{0}\right)\right)=\operatorname{Var}\left(\tilde{X}\left(\mathrm{M}_{0}\right)\right)+\operatorname{Var}\left(\hat{X}\left(\mathrm{M}_{0}\right)\right)-2 \operatorname{Cov}\left(\tilde{X}\left(\mathrm{M}_{0}\right), \hat{X}\left(\mathrm{M}_{0}\right)\right)
$$


Cov indicates the covariance.

$$
\begin{aligned}
& \operatorname{Var}\left(\hat{X}\left(\mathrm{M}_{0}\right)\right)=\operatorname{Var}\left(\sum_{j=1}^{j=N} \lambda_{j} X_{o}^{j}\right)=E\left(\sum_{j=1}^{j=N} \lambda_{j}\left(X_{o}^{j}\right)^{2}-\left(\sum_{j=1}^{j=N} \lambda_{j} E\left(X_{o}^{j}\right)\right)^{2}\right. \\
& \operatorname{Var}\left(\hat{X}\left(\mathrm{M}_{0}\right)\right)=\sum_{j=1}^{j=N} \sum_{l=1}^{l=N} \lambda_{j} \lambda_{l} E\left(X_{o}^{j} X_{o}^{l}\right)-\left(\sum_{j=1}^{j=N} \lambda_{j} E\left(X_{o}^{j}\right)\right)^{2}
\end{aligned}
$$

Assuming that the observation is homogeneous over the vicinity of $x_{0}$ (first intrinsic assumption) :

$$
E\left(X_{o}^{j}\right)=E\left(X_{o}^{l}\right)=m
$$

This assumption states that the mean of the difference between observations is independent of space and time separation. Therefore equation 9 leads to

$$
\begin{aligned}
& \operatorname{Var}(\hat{X}(\mathrm{M} 0))=\sum_{j=1}^{j=N} \sum_{l=1}^{l=N} \lambda_{j} \lambda_{l} E\left(\left(X_{o}^{j} X_{o}^{l}\right)\right)-\sum_{j=1}^{j=N} \sum_{l=1}^{l=N} \lambda_{j} \lambda_{l} m^{2} \\
& \operatorname{Var}(\hat{X}(M 0))=\sum_{j=1}^{j=N} \sum_{l=1}^{l=N} \lambda_{j} \lambda_{l} \operatorname{Cov}\left(X_{o}^{j}, X_{o}^{l}\right)
\end{aligned}
$$

Furthermore,

$$
\begin{gathered}
\operatorname{Cov}\left(\tilde{X}\left(\mathrm{M}_{0}\right), \hat{X}\left(\mathrm{M}_{0}\right)\right)=E\left(\left(\sum_{j=1}^{j=N} \lambda j X_{o}^{j}\right) X_{o}^{0}-m^{2}\right) \\
=\sum_{j=1}^{j=N} \lambda j \operatorname{Cov}\left(X_{o}^{j}, X_{o}^{0}\right)
\end{gathered}
$$

Therefore, using equations (4), (11), and (12):

$$
\operatorname{Var}\left(R\left(M_{0}\right)\right)=\operatorname{Var}\left(\tilde{X}\left(M_{0}\right)\right)+\sum_{j=1}^{j=N} \sum_{l=1}^{l=N} \lambda_{j} \lambda_{l} \hat{C}_{i j}-2 \sum_{j=1}^{j=N} \lambda_{j} \hat{C}_{i 0}
$$

Where $\hat{C}_{i j}=\operatorname{Cov}\left(\hat{X}\left(\mathrm{M}_{i}\right), \hat{X}\left(\mathrm{M}_{j}\right)\right)$

Minimizing functional $\operatorname{Var}\left(R\left(\mathrm{M}_{0}\right)\right)$ in weighting space and under unbiased and external drift constraints leads to the following linear system:

$$
\left\{\begin{array}{l}
\sum_{j=1}^{j=N} \lambda_{j} \hat{C}_{i j}-\mu_{1}-\mu_{2} Y i=\hat{C}_{i 0} \quad \text { for } i=1, N \\
\sum_{j=1}^{j=N} \lambda_{j}=1 \\
\sum_{j=1}^{j=N} \lambda_{j} Y_{j}=Y_{0}
\end{array}\right.
$$


$\mu_{1}$ and $\mu_{2}$ are the Lagrangian terms used to take into account the unbiased and external drift constraints.

The objective method requires parameterization of the spatial and temporal covariance structure of surface wind speed, zonal and meridional wind components, wind stress magnitude, and wind stress components. The approach used in Bentamy et al. (1996) is adapted for this study. First, the local spatial and temporal stationary is assumed. Therefore, the covariance does not depend on the precise geographical location and epoch of data, but only on separations in space and time:

$$
\operatorname{Cov}\left(\tilde{X}\left(\mathrm{M}_{i}, t_{i}\right), X\left(\mathrm{M}_{j}, t_{j}\right)\right)=C(\delta h, \delta t)
$$

Where $\delta h$ and $\delta t$ stand for spatial and temporal separation, respectively.

As the assessment of this assumption is not straightforward, the following assumption is considered:

$$
E\left(\left(\tilde{X}\left(M_{i}, t_{i}\right)-\tilde{X}\left(M_{j}, t_{j}\right)^{2}\right)=G(\delta h, \delta t)\right.
$$

Using the first intrinsic assumption (eq. 10):

$$
G(\delta h, \delta t)=2(C(0,0)-C(\delta h, \delta t))
$$

In practice, the following structure function, called a variogram, is used

$$
\Gamma(\delta h, \delta t)=C(0,0)-C(\delta h, \delta t)
$$

The objective is to determine the covariance matrix involving the main spatial and temporal structure of variable $\tilde{X}$ without any prior gridding or spectral filtering. Therefore, the investigation of covariance or variogram behavior as a function of space and time separations is performed over several areas of the Atlantic Ocean and the Mediterranean Sea. ASCAT wind retrievals are used to calculate the sample covariance. The observed values of $\tilde{X}$ are then calculated over each satellite WVC and stratified in terms of 1-hourly time windows (WVC time). For each temporal separation $(\delta t)$ varying between $0 \mathrm{~h}$ and $24 \mathrm{~h}$, the covariances of observations spatially separated by a distance $(\delta h)$ varying between $0 \mathrm{~km}$ and $500 \mathrm{~km}$ are estimated. Examples of wind speed, zonal and meridional component variogram behaviors as a function of spatial separation for a lag time less than one hour are shown in Figure 5.

In practice, all ASCAT validated retrievals occurring between 00h:00 and 23h:59mn:59sc UTC of a given day, are collected for daily averaged wind fields calculations, respectively

According to ASCAT sampling scheme (Figure 2), in order to reduce the impact of ECMWF wind estimates, extended observation periods are considered for daily ASCAT gridded wind field calculations. Indeed, considering retrievals occurring within a time interval of 12 hours bounding a day of interest, allows almost global coverage.

More specifically, if no ASCAT data are available at a given grid point and during the day of interest, the closest retrievals $X_{\mathrm{pr}}\left(x_{\mathrm{sat}}, y_{\mathrm{sat}}, t_{\mathrm{sat}}\right)$ occurring within $50 \mathrm{~km}$ from the grid point and on the prior day between 12h:00 and 24h:00 UTC, or on the following day between 00h:00 and 12h:00 UTC are selected. The temporally interpolated values 
of $X_{\mathrm{pr}}$ at $00 \mathrm{~h}: 00$ or at $24 \mathrm{~h}: 00$ of the day of interest are used as ASCAT observations for daily calculation.

The temporal interpolation approach is based on the complex empirical orthogonal function (CEOF) method. It aims to determine the advective patterns of wind variables through the determination of the amplitude and phase of the related signal. To achieve this, the twelve ECMWF analyses calculated one day prior, one day after, and during the day of interest are used.

ECMWF wind components $u_{\mathrm{m}}$ and $v_{\mathrm{m}}$ are used to define the following analytic signal:

$\mathrm{Z}(\mathrm{x}, \mathrm{y}, \mathrm{t})=\mathrm{u}_{\mathrm{m}}(\mathrm{x}, \mathrm{y}, \mathrm{t})+\mathrm{iv} \mathrm{m}(\mathrm{x}, \mathrm{y}, \mathrm{t}) ; \mathrm{i}^{2}=-1$

The correlation between data at pairs provides a new matrix:

$\mathbf{M}_{i j}=\frac{1}{L T} \sum_{n=1}^{T} Z^{*}\left(x_{i}, y_{i}, t_{n}\right) Z\left(x_{j}, y_{j}, t_{n}\right)$

Where $L$ represents the number of ECMWF grid points $\left(0.50^{\circ} \times 0.50^{\circ}\right), T$ is the number of analysis epochs (here 12 ), and $Z *$ is the complex conjugate of $Z$.

Matrix $\mathbf{M}$ is by definition Hermitian . Its elements are complex, except for diagonal elements, which are real. The eigenvector decomposition of $M$ gives:

$\sum_{j=1}^{L} \mathbf{M}_{i j} E_{p}\left(x_{j}, y_{j}\right)=\lambda_{p} E_{p}\left(x_{i}, y_{i}\right)$

$E_{p}$ and $\lambda_{p}$ are the eigenvector and eigenvalues, respectively. Their number is at most $P$ $=\min (L, T)$.

Assuming the Ep eigenvectors orthonormal, the analytic signal Z (19) can be re-written as:

$$
Z\left(x_{i}, y_{i}, t_{n}\right)=\sum_{p=1}^{P} E_{p}\left(x_{i}, y_{i}\right) S_{p}\left(t_{n}\right)
$$

$S p$ are the time series associated with the principal components of the CEOF method, defined as:

$$
S p\left(t_{n}\right)=\sum_{j=1}^{L} Z\left(x_{j}, y_{j}, t_{n}\right) E p\left(x_{j}, y_{j}\right)
$$

The complex vector $S_{p}$ is represented as:

$$
S_{p}\left(t_{n}\right)=R_{\mathrm{m}}\left(t_{n}\right) \exp \left(i \theta_{\mathrm{m}}\left(t_{n}\right)\right)
$$

Where $R_{\mathrm{m}}\left(t_{n}\right)$ and $\theta_{\mathrm{m}}\left(t_{n}\right)$ are the amplitude and the phase of $S_{p}\left(t_{n}\right)$, respectively.

For satellite observation time $\left(t_{\text {sat }}\right)$ occurring between $12 \mathrm{~h}: 00$ and $24 \mathrm{~h}: 00$ during the previous day, or between 00h:00 and 12h:00 during the following day with respect to day of interest, the amplitude and phase values are estimated through a weighted interpolation: 
$R_{\mathrm{m}}\left(t_{\mathrm{sat}}\right)=\sum_{n=1}^{T} \alpha_{n} R_{\mathrm{m}}\left(t_{n}\right)$ and $\theta_{\mathrm{m}}\left(t_{\mathrm{sat}}\right)=\sum_{n=1}^{T} \beta_{n} \theta_{\mathrm{m}}\left(t_{n}\right)$

Assuming a polynomial relationship between satellite observations and the ECMWF analysis

$R_{\mathrm{s}}\left(t_{\mathrm{sat}}\right)=f\left(R_{\mathrm{m}}\left(t_{\mathrm{sat}}\right)\right)$ and $\theta_{\mathrm{s}}\left(t_{\mathrm{sat}}\right)=g\left(\theta_{\mathrm{m}}\left(t_{\mathrm{sat}}\right)\right)$

Where $R_{s}$ and $\theta_{s}$ are the amplitude and phase of the satellite wind vector (retrieval).

Using polynomial functions $f$ and $g(26)$, values of $R_{\mathrm{s}}$ and $\theta_{\mathrm{s}}$ are estimated at $00 \mathrm{~h}: 00$ or at $24 \mathrm{~h}: 00$.

The temporal interpolation is first tested based on the use of synthetic data derived from ERA Interim wind products. For each ASCAT WVC occurring at $t_{\text {sat }}$, the ERA Interim wind vector that is closest in space and time is selected and assigned to WVC. The synthetic wind data are temporally interpolated using the above method. The results are compared to ERA Interim products estimated for 00h:00 or 18h:00. An illustration of such comparisons is shown in Figure 6. It indicates a synthetic wind vector at satellite time (Figure 6a), the temporally interpolated wind vector (Figure 6b), and the ERA Interim wind product ("true") (Figure 6c). Even though some differences between the interpolated and ERA Interim wind estimates are depicted, the temporal interpolation method tends to reproduce the ERA interim wind product in terms of wind speed as well as wind directions. The calculation of rms differences between "true" and temporal interpolated ERA Interim estimates, calculated during February 2009 and over global oceans, are about $1.80 \mathrm{~ms}^{-1}$ for wind speed, and about $2 \mathrm{~ms}^{-1}$ for both zonal and meridional wind components.

\section{Validation}

The previous method is used to estimate global daily wind fields from ASCAT retrievals with the spatial resolution of $0.5^{\circ}$ in longitude and latitude. They are referred to as DASCAT throughout the text. The estimated gridded surface parameters are similar to those derived from for QuikSCAT gridded wind field products (http://cersat.ifremer.fr/fr/data/discovery/by_parameter/ocean_wind/mwf_quikscat).

Figure 7 shows an example of ASCAT data, including observed (Figure 7a) and interpolated (Figure $7 \mathrm{~b}$ ) data, used to estimate gridded winds, and the resulting daily wind field (Figure 7c) for February 1, 2009.

\subsection{Assessment of the objective method}

The errors associated with the resulting DASCAT may have various sources, such as the accuracy of ASCAT retrievals, the ASCAT sampling scheme and the objective method. In section 3, the impact of the ASCAT sampling scheme is highlighted through the calculation of arithmetically averaging daily winds. This section deals with the investigation of the effects of ASCAT sampling and of the objective method (section 4) on the resulting daily estimates. The former is made by simulating ASCAT retrievals of ERA Interim winds and comparing daily averages, estimated using the objective method, with the "true" daily averages calculated as arithmetic means of the four numerical ERA Interim epochs (00h:00, 06h:00, 12h:00, 18h:00). The numerical model data are available every 6 hours and on a coarse grid of $1.50^{\circ}$ in longitude and latitude, 
while ASCAT WVC have a spatial resolution of $0.25^{\circ}$ and available with continuous time within scatterometer swaths. Therefore, for each ASCAT WVC that is the closest in space, ERA Interim estimates occurring within 3 hours from the WVC date are collected. The latter are linearly interpolated in space and time to determine the simulated ASCAT retrievals. The interpolation is performed for zonal and meridional components separately. The associated simulated wind speed is obtained as a magnitude of the interpolated components. Daily gridded wind fields are calculated from ERA Interim 6-hourly data, based on arithmetic averaging of the four epochs, and from the simulated ASCAT data using the objective method. It is found that the two daily wind fields exhibit very similar spatial and temporal patterns. Figure 8 shows the spatial distributions of correlations between the two daily zonal (Figure 8a) and meridional (Figure 8b) wind components for January-March 2009. The former exceed 0.85 for more than $95 \%$ of grid points. The associated first and third percentiles, and the median are about $0.91,0.97$, and 0.95 , respectively. The lowest correlations, about 0.72 , are found in the equatorial areas and especially for the meridional component in the Gulf of Guinea. This region is characterized by low winds (wind speed varying between $1 \mathrm{~ms}^{-1}$ and $4 \mathrm{~ms}^{-1}$ ) associated with highly variable wind directions. This is clear evidence that such lower correlation results from poor scatterometer sampling in the tropics (Figure 7), and from the inability of the objective method to recover accurate daily estimates in some specific areas.

The quality of the objective method is also investigated through its ability to reproduce ASCAT observations. To examine this, daily averaged winds calculated as arithmetic means from available ASCAT retrievals (L2b), and indicated as ASCAT L3 data, are computed over the DASCAT grid map for 2008-2009. On average, the number of ASCAT retrievals occurring daily within each grid point $\left(0.50^{\circ} \times 0.50^{\circ}\right)$ is about 5 . However, it varies significantly from high latitudes where it reaches 18, to the Equator where it does not exceed 2. For each scatterometer swath, only the valid and closest of grid point center retrievals is selected for ASCAT $\angle 3$ daily-averaged data calculation. Statistical parameters characterizing the difference between ASCAL L3 and DASCAT data are estimated. Similar statistics are calculated for ASCAT L3 and daily ECMWF winds (DECMWF). The latter are estimated as arithmetic means from the four daily analyses. The comparisons of the two statistical estimates highlight the ASCAT contributions to daily wind estimates, and how the resulting wind fields differ from DECMWF data. Indeed, ECMWF analyses are used as external drift and as a basis for the temporal interpolation of ASCAT retrievals (eq. 25 and 26). Overall, the mean difference between ASCAT L3 and DASCAT wind speed time series at each grid point and for 2008-2009, is close to zero $\left(0.05 \mathrm{~ms}^{-1}\right)$, and $97 \%$ of grid points exhibit standard deviations $\left(\sigma_{D A S C A T}\right)$ of wind speed differences varying between $0.50 \mathrm{~ms}^{-1}$ and $2 \mathrm{~ms}^{-1}$ (not shown). To further assess the ability of the objective method results to recover ASCAT observations, the Brier Skill Score (BSS) is calculated (Weiss et al, 2005). BSS is defined as $1-\left(\sigma_{\text {DASCAT }}\right)^{2} /\left(\sigma_{\text {DECMWF }}\right)^{2}$ if $\sigma_{\text {DASCAT }}$ is less than $\sigma_{\text {DECMWF, or as }}\left(\sigma_{\mathrm{DECMWF}}\right)^{2} /$ $\left(\sigma_{\text {DASCAT }}\right)^{2}-1$ if $\sigma_{\text {DASCAT }}$ is greater than $\sigma_{\text {DECMWF }} . \sigma_{\text {DASCAT }}$ and $\sigma_{\text {DECMWF }}$ are the standard deviations of wind speed difference time series of ASCAT L3 and DASCAT, and between ASCAT $L 3$ and DECMWF at each grid point of DASCAT grid map. Figure 9 shows the spatial distribution of BSS estimated for 2008-2009. More than $96 \%$ of BSS values are positive meaning that $\sigma_{D A S C A T}$ are lower than $\sigma_{D E C M W F}$ and therefore ASCAT retrievals have a higher impact on DASCAT estimates than ECMWF analyses. The highest BSS positive values (exceeding 0.6) are found at latitudes north of $40^{\circ} \mathrm{N}$ and south of $40^{\circ} \mathrm{S}$. In these regions the objective method tends to accurately reproduce the scatterometer observations. In some regions, such as inter-tropical areas and the Mediterranean Sea, the BBS has much smaller positive values. They illustrate the impact of sampling scheme of ASCAT and/or of spatial and temporal wind variability in these specific regions, yielding to an increase in departure of DASCAT from observations. The lowest negative values are found along $30^{\circ} \mathrm{S}$ off the Chilean coast. 
The variability of ASCAT L3 and DASCAT wind speed differences is slightly higher than for ASCAT L3 and DECMWF. This is mainly related to some atmospheric events associated to fronts or to sharp wind gradients. For instance, difference between ASCAT L3 and DASCAT winds exceeds $5 \mathrm{~ms}^{-1}$ on 9 March 2008 that has significant impact on standard deviation estimation. The one ASCAT swath available for this day indicates wind speed varying sharply from $2 \mathrm{~ms}^{-1}$ through $10 \mathrm{~ms}^{-1}$ along a distance of $100 \mathrm{~km}$ (not shown).

\subsection{In-situ comparisons}

The quality of the resulting wind fields DASCAT is mainly investigated through comprehensive comparisons with averaged buoy wind data. The results are provided for daily winds estimated during 2009. Daily buoy estimates are calculated as the arithmetic mean of all associated valid hourly data. For each day of 2009 , all daily buoy and ASCAT data located within $50 \mathrm{~km}$ are selected. Consequently, 3135 collocations from MFUK, 5942 from NDBC, and 5439 from tropical networks (PIRATA, RAMA, and TAO), with wind speeds ranging from 1 to $25 \mathrm{~ms}^{-1}$ met all the collocation quality control criteria. Figure 10 illustrates the comparison results for wind speeds (first column) and directions (second column). In general, both DASCAT daily wind speeds and directions compared well to buoy estimates. No systematic biases are depicted in the two variables.

More specifically, the wind speed biases are quite low and do not exceed $0.25 \mathrm{~ms}^{-1}$. The lowest value is found from DASCAT and tropical buoy data and is about $0.08 \mathrm{~ms}^{-1}$, whereas ASCAT and NDBC comparisons exhibit the highest bias value of $-0.23 \mathrm{~ms}^{-1}$, leading to a slight overestimation of satellite daily wind speed. The root mean square (rms) difference values are $1.37 \mathrm{~ms}^{-1}, 1.24 \mathrm{~ms}^{-1}$, and $1.11 \mathrm{~ms}^{-1}$ for MFUK, NDBC, and tropical comparisons, respectively. The three values are smaller than the gridded wind field requirement of $2 \mathrm{~ms}^{-1}$. For wind direction, the biases are negligible while the associated rms values are about $20^{\circ}, 25^{\circ}$, and $20^{\circ}$. Excluding daily buoy values less than $3 \mathrm{~ms}^{-1}$ lead to reductions of rms values to $18^{\circ}, 20^{\circ}$, and $16^{\circ}$. Such results are very similar to those obtained from ASCAT L2b (retrievals) and buoy hourly comparisons (Bentamy et al, 2008).

The differences between buoy and DASCAT daily wind estimates are investigated according to several parameters such as wind speed ranges, geographical locations, and wind variability. The results of difference behaviors as a function of wind speed condition, and as a function of buoy location are similar to behaviors characterizing the difference between collocated ASCAT L2b and hourly buoy wind data. DASCAT estimates tend to be overestimated (resp. underestimated) for low buoy winds (resp. high buoy winds). They are slightly overestimated at buoys located near shore. The rms daily wind speed difference does not exhibit any significant trend as a function of buoy wind speed ranges. As expected, and with respect to the results of section 3 related to the impact of ASCAT sampling scheme impact, interesting features are found when rms difference is investigated according to both buoy speed ranges and buoy daily variability. The latter is estimated as one standard deviation of wind speed series used to estimate buoy daily data. More than $98 \%$ of buoy wind speed variability values are lower than $4 \mathrm{~ms}^{-1}$. The discrepancy between daily buoy and DASCAT winds tend to be more associated with variability than with wind speed ranges (Figure 11). Indeed, for buoy variability lower than $2 \mathrm{~ms}^{-1}$, the rms difference is mostly lower than $1.5 \mathrm{~ms}^{-1}$. Most of rms values varying between $1.5 \mathrm{~ms}^{-1}$ and $2 \mathrm{~ms}^{-1}$ are clearly found for buoy variability exceeding $2 \mathrm{~ms}^{-1}$. 


\section{ASCAT Wind Field Patterns.}

\subsection{Global results}

This section aims to assess the spatial and temporal patterns of DASCAT gridded winds and to investigate their comparisons to those derived from ECMWF analyses (DECMWF) and from ERA-Interim re-analyses (DERA). Numerical daily wind estimates are calculated as arithmetic means of the associated four NWP data available at 00h:00, 06h:00, 12h:00, and 18h:00, and spatially interpolated over DASCAT daily grids $\left(0.50^{\circ} \times 0.50^{\circ}\right)$. The inter-comparisons are mainly based on the investigations of the annual means, standard deviations, root mean square wind differences, and on surface wind correlations over global ocean.

The mean structures of surface winds estimated from DASCAT fields during 2008 2009 are presented in Figure 12. The annual mean of wind speed and direction (Figure12 a) exhibit the main known large-scale characteristics. In the Northern Hemisphere, surface winds are mainly southwest-northeast oriented, while in the Southern Hemisphere, they are northwest-southeast oriented. The highest winds are found in the former oceanic regions. The Atlantic and Pacific inter-tropical regions are characterized by the trade winds, and low winds at the equator. The variability of wind speed, zonal and meridional wind components are shown in Figure 12 b), c), and d), respectively. As expected, the highest wind variability values are first found in North Atlantic and Pacific oceans, related to easterly spatial and temporal variability, and along the Southern Hemisphere associated with high easterly winds. The expected high wind variabilities related to the seasonal patterns of Indian monsoon and the southern area, and to the ITCZ moving are clearly depicted. These DASCAT spatial patterns are in very good agreement with DECMWF and DERA daily data (not shown). The overall biases between DASCAT and numerical model estimates are quite low and are less than $0.10 \mathrm{~ms}^{-1}$. More than $80 \%$ of annual mean wind speed differences located between $60^{\circ} \mathrm{S}$ and $60^{\circ} \mathrm{N}$ do not exceed $0.20 \mathrm{~ms}^{-1}$. DASCAT annual mean wind speed tend to be slightly higher (resp. lower) than DECMWF and DERA Interim in the tropical and extra-tropical regions (resp. in mid- and high-latitude areas). Such findings meet the results derived from collocated ASCAT retrievals (L2b) and ECMWF analysis data comparisons (Bentamy et al, 2008). The highest discrepancies between DASCAT and NWP estimates are found along the equatorial areas, where the bias values reach 0.50 $\mathrm{ms}^{-1}$. The only exception is depicted along the equator in the eastern Pacific region, where the mean bias is negative (underestimation of DASCAT winds) and is about of $0.20 \mathrm{~ms}^{-1}$. Such behaviors might be related to SST effect on surface wind variation (Chelton et al, 2005). To further investigate ASCAT and numerical model data comparisons, the rms differences between DASCAT and DECMWF, and between DASCAT and DERA daily estimates are computed. Figure 13 shows the features of the rms differences for wind speed and the associated wind components. The former are highly correlated to regional wind variability (Figure $12 \mathrm{~b}$ ), c), and d)). They are characterized by an anisotropic pattern with two main orientations: meridional in tropical and extra-tropical, and zonal in mid- and high-latitudes regions. The highest rms difference values, exceeding $1.5 \mathrm{~ms}^{-1}$, are found north $50^{\circ} \mathrm{N}$ and south $50^{\circ} \mathrm{S}$. High rms values, exceeding $1 \mathrm{~ms}^{-1}$, are also found along the equatorial zone and especially for wind components.

\subsection{Time Series}

The above results indicate that, although the surface wind patterns calculated from DASCAT and numerical daily estimates compare well, they clearly exhibit some local differences. Figure 14 illustrates such results. It shows daily wind speed time series at five oceanic locations: a) $\left(55^{\circ} \mathrm{N}, 13^{\circ} \mathrm{W}\right)$; b) $\left(42 \mathrm{~N}, 4.7^{\circ} \mathrm{E}\right)$; c) $\left(0^{\circ} \mathrm{N}, 10^{\circ} \mathrm{W}\right)$; d) $\left(10^{\circ} \mathrm{N}\right.$, 
$\left.55^{\circ} \mathrm{E}\right)$; e) $\left(50^{\circ} \mathrm{S} ; 90^{\circ} \mathrm{E}\right)$. To assess the time series comparisons, daily averaged $A S C A T$ $L 3$ wind data are also used and shown in Figure 14. The three sources exhibit very similar temporal patterns. At the North Atlantic location (Figure 14a), they retrieve the main representative large-scale wind features in the area. The temporal wind structure is mainly characterized by robust wind seasonality; with a single maximum and minimum occurring in winter and summer, respectively. At the location of the Gulf of Lion in the Mediterranean Sea (Figure 14b) the surface wind speeds derived from the three sources exhibit quite similar temporal features than those in the North Atlantic Ocean. The time series of wind speed at the equatorial site (Figure 14c) display lower seasonality features. Generally speaking, surface winds vary between $2 \mathrm{~ms}^{-1}$ and 6 $\mathrm{ms}^{-1}$, with two peaks occurring in the fall and spring. In the Indian Ocean (Figure 14d), the time variations of wind speed are characterized by a remarkable double-peak pattern. The primary peak occurs in July when the summer monsoon is active, while the secondary peak occurs in January when the region experiences winter. The difference between the two peaks underlines that the regional climate is overwhelmingly controlled by the monsoon event. As expected the highest winds are found at the location in the Southern Ocean (Figure 14e), where the minimum exceeds $5 \mathrm{~ms}^{-1}$. The annual variations are generally small and are approximately half of the seasonal signals found in the northern site. However, the wind patterns display a maximum and a minimum occurring during Northern Hemisphere summer and winter seasons. Very similar wind features are found for ERA Interim (not shown). Figure 14 underlines the local and/or temporal amplitude differences between satellite and numerical daily estimates. As expected, ASCAT $\angle 3$ data are accurately retrieved by DASCAT estimates. Indeed, the correlation coefficient exceeds 0.95 except at the equatorial location (Figure 14c), where it drops to 0.85 . The associated correlations characterizing ASCAT and ECMWF comparisons are lower than 0.95 with a minimum of 0.57 at equator. Furthermore, the rms values range between $0.62 \mathrm{~ms}^{-1}$ (Indian location) and $1.24 \mathrm{~ms}^{-1}$ (North Atlantic location) for ASCAT L3 and DASCAT, and between $1.07 \mathrm{~ms}^{-1}$ and $2.17 \mathrm{~ms}^{-1}$ for ASCAT L3 and ECMWF differences. One should notice that no significant linear relationship is found between ASCAT and ECMWF differences and daily ECMWF variability (estimated from the four analysis). The seasonal variation of the wind speed discrepancy between ASCAT L3 and DASCAT is mainly visible at the site in the Indian Ocean (Figure 14d). Such departure may be related to the impact of the ECMWF wind analysis on the resulting daily wind fields through the use of temporal interpolation (see eq. 19 through 26). Similar seasonal behavior is found between ASCAT L3 and ECMWF at the equatorial location, but with very little impact on DASCAT results. This is related to the steady wind in this region (Figure 13). Figure 14 indicates that most high-wind conditions retrieved from ASCAT measurements are underestimated by both DASCAT and ECMWF. For instance, at locations in the North Atlantic, Mediterranean Sea, and South Atlantic, where the highest winds are depicted, the percentages of wind speeds exceeding $12 \mathrm{~ms}^{-1}$ versus total valid data are, 23\%, 21\%, and 58\% for ASCAT, $19 \%, 18 \%$; and $54 \%$ for DASCAT, and $16 \%, 15 \%$, and $49 \%$ for ECMWF, respectively. Improvements are also depicted for time series of wind direction comparisons. Indeed, the DASCAT analysis has an rms directional difference of approximately $16^{\circ}$ to the ASCAT data, except at the Mediterranean location (Figure 14b) where it reaches $22^{\circ}$. The latter is an area of high variable winds (Bentamy et al, 2009).

\subsection{High Wind Conditions}

One of the main uses of scatterometer gridded wind fields is to characterize the global statistical distributions of high wind conditions (e.g. Liu et al, 2008). Using ASCAT retrievals, the spatial distribution of high scatterometer winds (not shown) exceeding 20 $\mathrm{ms}^{-1}$ and estimated during $2008-2009$, indicates that high winds occur in polar and mid-latitudes related to strong westerlies and/or to winter storms. High winds are also 
observed in some specific regions such Gulf of Lion in the Mediterranean Sea related to the Mistral wind. The lowest occurrences are found in the inter-tropical area. They are mainly associated to tropical storms and hurricane events. Such events may have rapid spatial and temporal variabilities that cannot be recovered by daily ASCAT wind estimates (DASCAT). The objective is to evaluate the ASCAT sampling scheme and objective method impacts on DASCAT high wind estimates. It is achieved through the examination of DASCAT high winds against ASCAT observations and numerical analyses. Investigations are performed for high wind events associated with tropical cyclones occurring in the Atlantic, Pacific, and Indian Oceans, and to the Mistral occurring in the Mediterranean Sea. The tropical cyclones (Sampson and Schrader, 2000) are considered along with their geographical coordinates every 6 hours (00h:00, 06h:00, 12h:00, 18h:00 UTC) and their intensity. They are extracted from the NOAA real-time tropical cyclone products archive (http://rammb.cira.colostate.edu/products/tc_realtime). During 2008, the reported tropical cyclone numbers are 17, 45, 7, and 29 in the Atlantic, Pacific, Indian, and Southern Oceans, respectively. All ASCAT L2b data occurring within $25 \mathrm{~km}$ and 3 hours from cyclone locations and dates are selected. ECMWF, available on the same cyclone dates, and DASCAT, available on the same cyclone dates, that are each within $25 \mathrm{~km}$ of the cyclone location are collocated. The collocation procedure yields to 338, 1527, and 1772 collocated data numbers for ASCAT L2b, DASCAT, and ECMWF, respectively. Only collocated data available for the same cyclone locations and dates are considered for comparison purposes (Figure 15). Even though more than $88 \%$ of collocated wind speeds exceed $10 \mathrm{~ms}^{-1}$, some lower winds are found that may be related to the dislocation of cyclones as retrieved from ASCAT with respect to the reported locations. The scatterplots indicates that ASCAT L2b and DASCAT (Figure $15 \mathrm{a}$ ) wind speeds compare fairly well. The associated correlation coefficient is 0.83 , improving the correlation between ASCAT L2b and ECMWF (Figure 15c), which is 0.57. As expected, DASCAT wind speeds are underestimated with respect to ASCAT L2b. Furthermore, the difference between the two sources is wind speed dependent as shown for winds exceeding $20 \mathrm{~ms}^{-1}$. Overall, the mean and rms differences between ASCAT L2b and DASCAT are $1.89 \mathrm{~ms}^{-1}$ and $3.32 \mathrm{~ms}^{-1}$. The discrepancy between ASCAT L2b and DASCAT is partly due to the objective method and to the ASCAT sampling scheme, yielding, in some cases, to wind smoothing and/or to inexact spatial collocation. Excluding ASCAT L2b and DASCAT differences exceeding two standard deviations of the difference series, the bias is reduced to $1.29 \mathrm{~ms}^{-1}$ and the rms is 2.44 $\mathrm{ms}^{-1}$. ASCAT L2b and ECMWF comparison provides much higher statistical parameters. The bias and rms differences are $4.40 \mathrm{~ms}^{-1}$ and $6.39 \mathrm{~ms}^{-1}$, respectively. The wind direction comparisons (Figures $15 \mathrm{~b}$ and d) exhibit high scatter between the three sources. Indeed, the standard deviation of ASCAT and DASCAT, and between ASCAT L2b and ECMWF differences are about $66^{\circ}$ and $69^{\circ}$, respectively. The associated biases are $-7^{\circ}$ and $12^{\circ}$ indicating that satellite data and analyses are blowing more toward low pressure than NWP analyses.

The ability of daily ASCAT gridded winds to reproduce high wind conditions as retrieved from ASCAT measurements, is investigated in the western area of the Mediterranean Sea limited by $39^{\circ} \mathrm{N}-44^{\circ} \mathrm{N}$ in latitudes, and $2^{\circ} \mathrm{E}-9^{\circ} \mathrm{E}$ in longitude. Although the study area is quite small, more than $32 \%$ of ASCAT retrievals exceeding $15 \mathrm{~ms}^{-1}$ in the Mediterranean Sea are found in this oceanic region. Most of the high winds are related to the Mistral, a strong northwesterly wind blowing through the Rhône valleys and then into the Gulf of Lion. Most Mistral events occur during winter and spring seasons, though they also occur in summer and fall seasons. They may last for one or several days (Cavaleri, 2005). Mistral wind occurrences during $2008-2009$ are from Météo-France (http://france.meteofrance.com/france/climat_france). ASCAT may provide wind observations twice a day, over the study area at about 10am and 10pm UTC. They are used to calculate arithmetic daily mean ASCAT L3 (see above) over the same grid map as DASCAT $\left(0.50^{\circ} \times 0.50^{\circ}\right)$. The total amount of available collocated and 
valid ASCAT L3, DECMWF, and DASCAT data for Mistral events during 2008-2009 is 47487. Overall, the wind speed mean and standard deviation, both estimated from ASCAT L3 estimates, are $6.57 \mathrm{~ms}^{-1}$ and $3.86 \mathrm{~ms}^{-1}$. Similar global statistics are found for DASCAT and DECMWF. Furthermore, the main spatial and temporal patterns depicted from ASCAT data are successfully replicated by DASCAT, and meet those exhibited by ECMWF (not shown). Major differences between ASCAT and analysis wind speeds arise in high wind conditions. Indeed, more than $10 \%$ of ASCAT retrievals exceed $12 \mathrm{~ms}^{-1}$, and about $5 \%$ exceed $15 \mathrm{~ms}^{-1}$. These rates are reduced to $7.59 \%$ and $2.14 \%$ for DASCAT, and to $6.69 \%$ and $1.66 \%$ for ECMWF. To better illustrate how DASCAT replicates scatterometer winds and how they may be used to characterize the wind distributions over the westernmost Mediterranean Sea, comparisons are performed for Mistral events. During 2008-2009, 66 events have been reported with durations of 1 to about ten days yielding to 148 Mistral days. Most high winds, from ASCAT data, are found in a region including Gulf of Lion $\left(40.5^{\circ} \mathrm{N}-43.5 \mathrm{~N}^{\circ} ; 3.5^{\circ} \mathrm{E}-7.5^{\circ} \mathrm{E}\right)$. For comparison purposes (Figure 16), every day, the maximum wind speeds derived from ASCAT L3, DASCAT, and DECMWF are selected. About $50 \%$ of ASCAT L3 and DASCAT daily maximum winds are located at the same grid points, whereas $83 \%$ are found at adjacent grid points. The selected high winds from ASCAT L3 yield to mean and third percentile values of $15.15 \mathrm{~ms}^{-1}$ and $17.83 \mathrm{~ms}^{-1}$. Both DASCAT and DECMWF analyses tend to be under-estimated versus ASCAT L3. The related mean biases (resp. standard deviations) are $0.85 \mathrm{~ms}^{-1}$ (resp. $1.66 \mathrm{~ms}^{-1}$ ) and $1.18 \mathrm{~ms}^{-1}$ (resp. $1.98 \mathrm{~ms}^{-1}$ ). As shown in Figure 16, the departures of DASCAT (Figure 16a) and DECMWF (Figure 16c) from ASCAT $L 3$, are wind speed range dependent. For ASCAT $L 3$ winds exceeding $17.83 \mathrm{~ms}^{-1}$, the biases increase to $1.42 \mathrm{~ms}^{-1}$ for DASCAT, and to $2.75 \mathrm{~ms}^{-1}$ for DECMWF. The related difference standard deviations are close to the overall values. Factors such as high-frequency wind variability, spatial variability, and spatial and temporal collocations may contribute to explain the discrepancies between ASCAT L3 and DASCAT winds. However, due to Mistral patterns, the wind direction comparisons (Figures $16 \mathrm{~b}$ and $\mathrm{d}$ ) indicate that DASCAT successfully reproduce scatterometer wind directions. The mean and standard deviation of ASCAT L3 and DASCAT wind directions are $1^{\circ}$ and $19^{\circ}$, respectively. ASCAT $L 3$ and DECMWF difference has similar statistics.

\section{Summary and perspectives}

The determination of long time series of gridded wind fields from remotely sensed data are needed for various scientific and operational topics (see for instance www.myocean.eu.org). Such regular in space and time products have been calculated from QuikSCAT retrievals from July 1999 through November 2009. The objective of this study is to estimate daily wind fields from ASCAT wind observations with similar spatial resolution $\left(0.50^{\circ} \times 0.50^{\circ}\right)$ than QuikSCAT analyses. In future, the two scatterometer wind fields will be used to estimate consistent long time series that will be used to enhance oceanic forcing function determination, to better determine surface wind statistical distributions at global and regional scales, and to characterize the spatial and temporal patterns of surface winds and the related parameters (wind divergence, wind stress curl, turbulent fluxes). They will be calculated using the same objective method and the statistical parameters characterizing the differences between QuikSCAT and ASCAT retrievals.

For this study, the resulting wind fields are calculated based on a geostatistical method with external drift. Remotely sensed data from ASCAT are considered as observations while numerical model analysis (ECMWF) are associated with the external drift. The spatial and temporal structure functions for wind speed, zonal, and meridional wind components are estimated from ASCAT retrievals. Furthermore, the new procedure 
includes a temporal interpolation of the retrievals, based on CEOF approach, in order to enhance the sampling length of the scatterometer observations. The resulting daily wind fields involves the main know surface wind patterns as well as some variation modes associated with temporal and spatial moving features. The accuracy of the gridded winds is investigated through comparisons with moored buoy data. The latter, derived from NDBC, MFUK, PIRATA, RAMA, and TAO, are daily-averaged and collocated in space and time with the wind fields. The results of the matchup analysis confirm the ability of daily satellite wind field to retrieve valuable surface wind speeds and directions. The rms differences for wind speed and direction are about $1.50 \mathrm{~ms}^{-1}$ and $20^{\circ}$. The rms behaviors as function of in-situ wind speed ranges are similar to those obtained from ASCAT L2b and buoy comparisons.

At global and regional scales, the daily gridded winds are compared to surface winds derived from ECMWF analysis and from ERA Interim data as well as to ASCAT L3 data. The four sources provide quite similar large-scale features. The main discrepancies are found at small scales and in terms of wind amplitude. The two numerical models underestimate winds compared to those measured by satellites. Even tough, the procedure used to generate daily wind fields result in smoothing of the original scatterometer observations, the study indicates the ability of DASCAT to reproduce in satisfactory manner wind speed and direction features as derived from ASCAT retrievals.

\section{Acknowledgements}

The authors are grateful to ECMWF, EUMETSAT, CERSAT, GODIVA, JPL, MétéoFrance, NDBC, O\&SI SAF, PMEL, and UK MetOffice, for providing the buoy, numerical, and satellite data used in this study. Thanks are due to Anthony Santorelli for providing comments on the manuscript.

\section{References}

Bentamy, A., Y. Quilfen, F. Gohin, N. Grima, M. Lenaour, J. Servain, 1996: Determination and validation of average field from ERS-1 scatterometer measurements. Global Atmosphere and Ocean System, vol. 4, 1-29.

Bentamy, A., N. Grima, and Y. Quilfen, 1998: Validation of the gridded weekly and monthly wind fields calculated from ERS-1 scatterometer wind observations. Global Atmosphere and Ocean System, vol. 6, 373-396.

Bentamy, A., K B. Katsaros, M. Alberto, W. M. Drennan, E. B. Forde, 2002: Daily surface wind fields produced by merged satellite data. American Geophysical Union, Geophysical Monograph Series vol. 127, 343-349.

Bentamy, A., 2008: High spatial and temporal wind fields 1996 - 2006. Report on Surface Wind Fields. PPR-Glorys. LOS/Ifremer publication. 26p.

Bentamy, A.; D. Croize-Fillon, P. Queffeulou; C. Liu, H. Roquet, 2009: Evaluation of high-resolution surface wind products at global and regional scales. Journal of Operational Oceanography, vol. 2, 15-27(13).

Cavaleri, L, 2005: The wind and wave atlas of the Mediterranean Sea -the calibration phase. Advances in Geosciences, 2, 255-257, ID: 1680-7359/adgeo/2005-2-255.

Chelton, D. B. and M. H. Freilich, 2005: Scatterometer-based assessment of 10-m wind analyses from the operational ECMWF and NCEP numerical weather prediction models. Monthly Weather Review, vol 133, 409-429. 
Perrie, W., E. Dunlap, P. W. Vachon, B. Toulany, R. Anderson, and M. Dowd, 2002: Marine wind analysis from remotely sensed measurements. Canadian Journal of Remote Sensing, vol. 28, 450-465.

Liu, W. T., W. Tang, X. Xie, P. P. Niiler, 2008: Wind power distribution over the ocean, Geophys. Res. Lett. 35, pp. L13808,.doi:10.1029/2008GL034172.

Royle, J. A., L. M. Berliner, C. K. Wikle, and R. F. Milliff, 1999: A hierarchical spatial model for constructing wind fields from scatterometer data in the Labrador Sea. Case Studies in Bayesian Statistics IV, C. Gatsonis, Ed., Springer-Verlag, 367382.

Sampson, C. R., and A. J. Schrader, 2000: The automated tropical cyclone forecasting system (Version 3.2). Bulletin American Meteorology Society , 81, 1131-1240.

Tang, W., W.T. Liu, 1996: Objective interpolation of scatterometer winds. JPL Publication, 96-19, Jet Propulsion Laboratory, Pasadena, California, 16pp.

Wackernagel, H., 1998. Multivariate geostatistics. Springer, Berlin, 291pp.

Weisse, R., H. Von Storch, and F. Feser, 2005: Northeast Atlantic and North Sea storminess as simulated by a regional climate model during 1958-2001 and comparison with observations. Journal of Climate, vol. 18, 465-479.

Woiccshyn, P.. M., M. G Wurtel, G. F. Cunningham, 1989: Wave hindcasts forced by scatterometer and other wind fields, $2^{\text {nd }}$ International Workshop on wave hindcasting and forecasting, vol. 18, 465-479. 
Figures

Figure 1: ASCAT measurement principle (Courtesy Eumetsat)

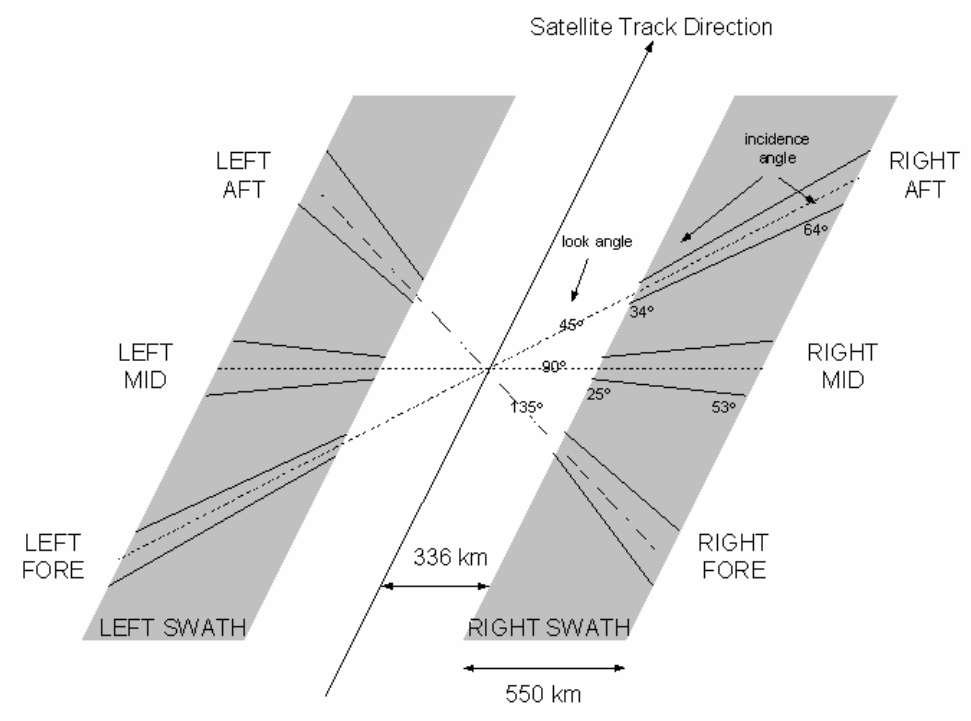


Figure 2: a) ASCAT wind speed retrievals occurring on January $1^{\text {st }}, 2009$. b) Sampling length distribution of ASCAT valid wind speeds collected during $1^{\text {st }}$ trough $29^{\text {th }}$ January 2009.
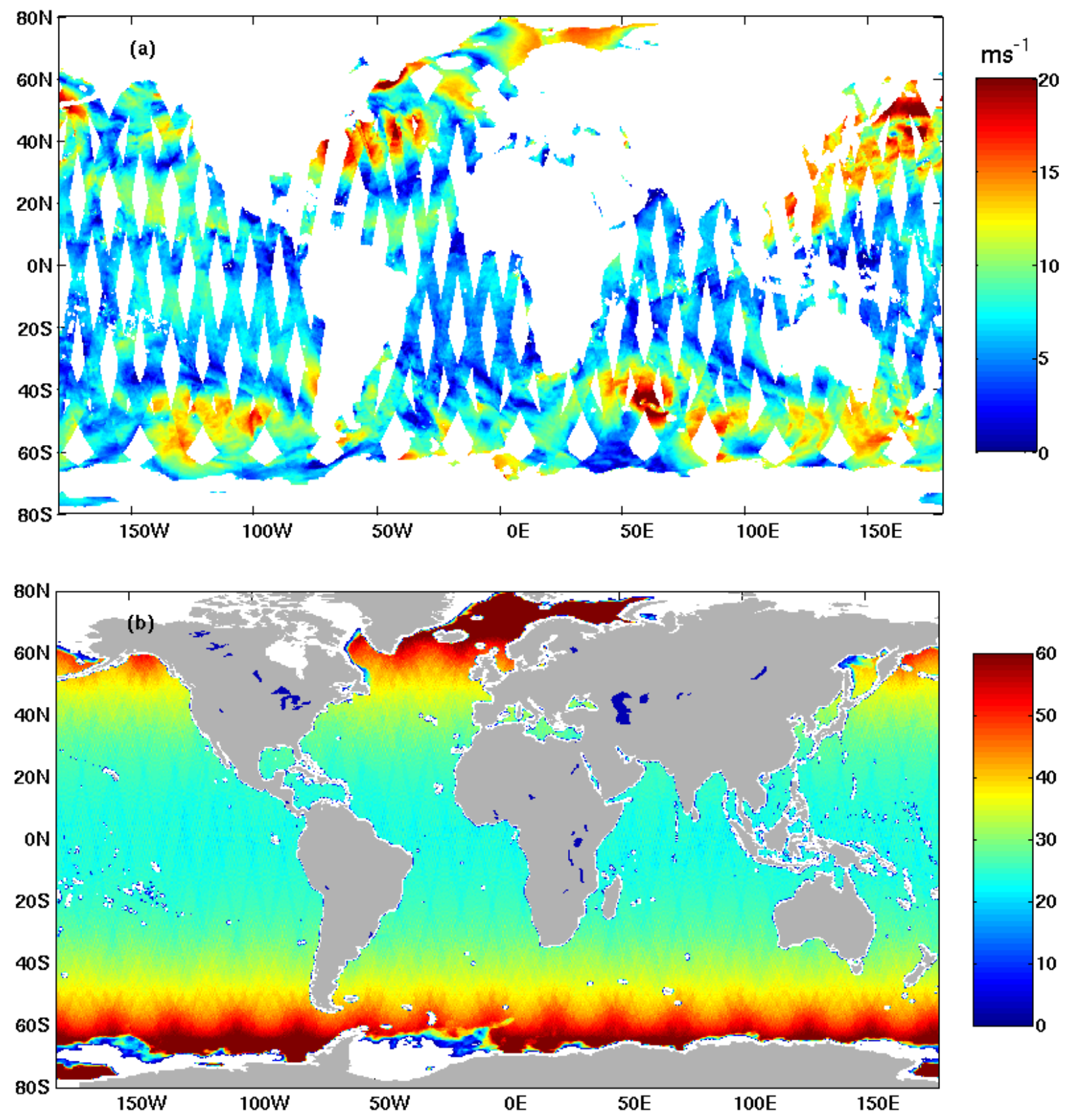
Figure 3: Mean differences between daily wind speeds calculated from buoy raw (hourly) data and from buoy data occurring at ASCAT passes
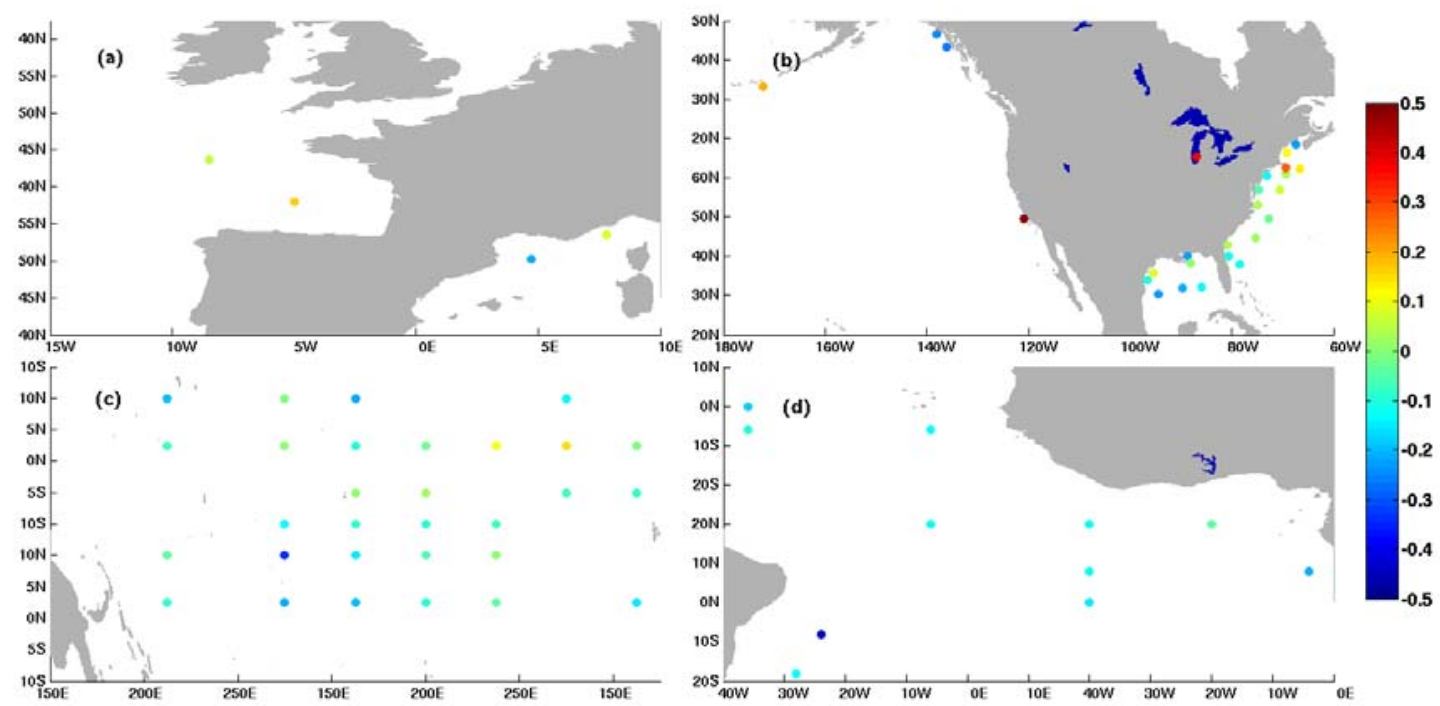

Figure 4 : Standard deviations of differences between daily wind speeds calculated from buoy raw (hourly) data and from buoy data occurring at ASCAT passes

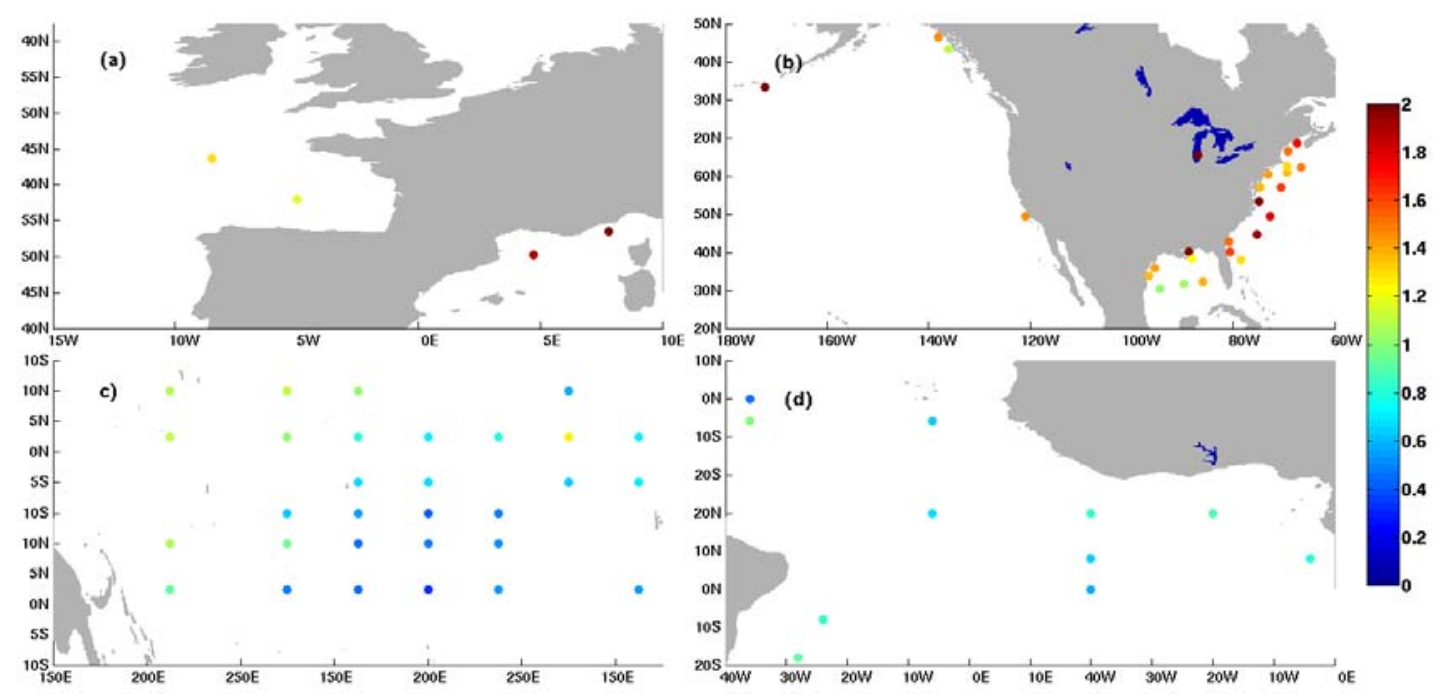


Figure 5: Variogram function of $\tilde{X}$ variable estimated over $5^{\circ} \times 5^{\circ}$ boxes in the Mediterranean Sea and in the Atlantic Ocean for lag time less than 1hour. The boxes are centered at $5^{\circ}$ intervals of longitude and longitude $4^{\circ} \mathrm{E}-42^{\circ} \mathrm{N}$ (first row); $5^{\circ} \mathrm{W}-45^{\circ} \mathrm{N}$ (second row); $10^{\circ} \mathrm{W}-0^{\circ} \mathrm{N}$ (third row). The spatial structure is estimated for wind speed $(a ; d ; g)$, zonal wind component $(b ; e ; h)$, and for meridional component $(c ; f ; i)$ differences
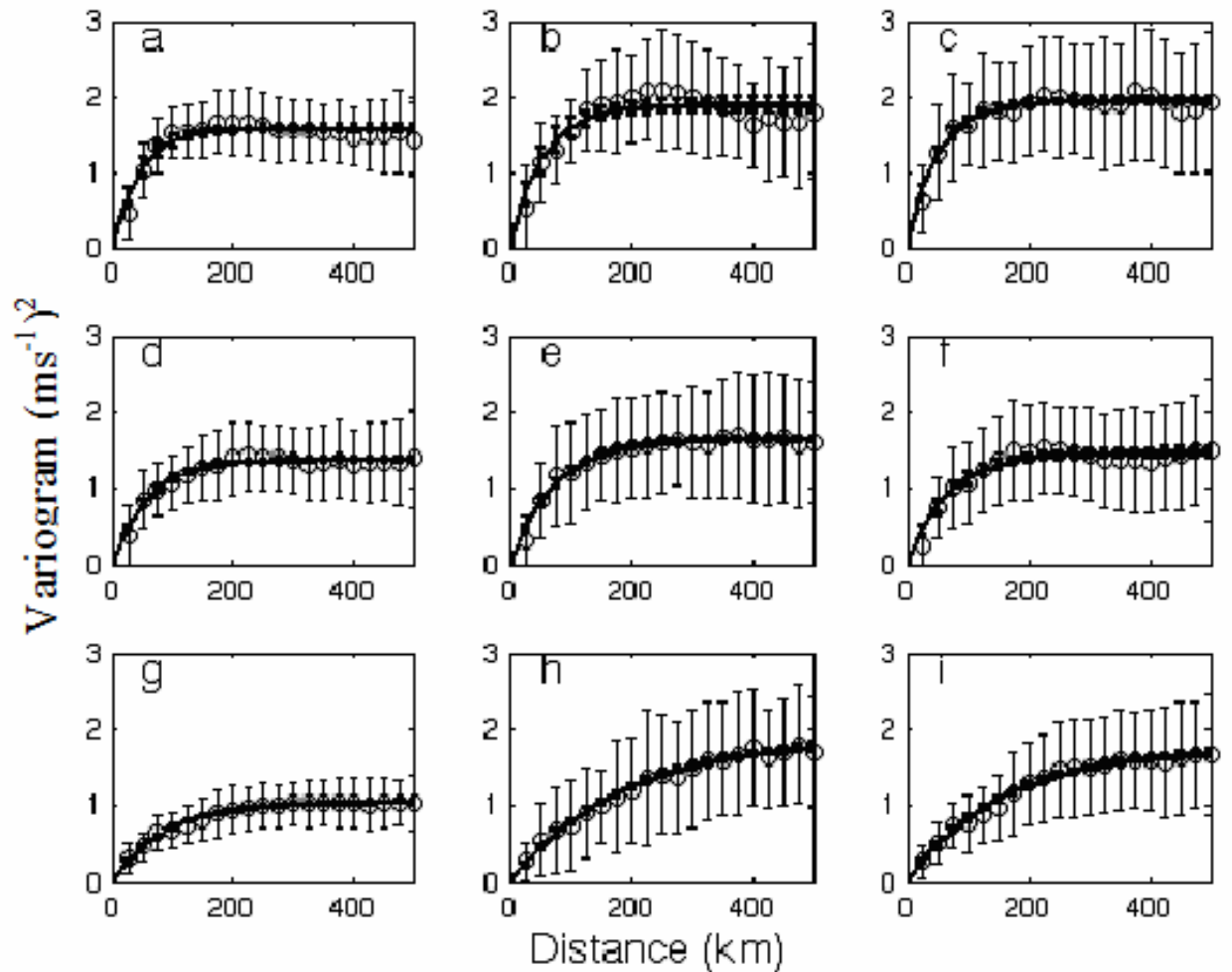
Figure 6: Example of temporal interpolation result. a): Synthetic data occurring 12h:00 and 23h:59mn:59sc on January, 30 2009. b): Temporal interpolated wind vector at 00h:00 on February 1 2009. c): ERA Interim wind vector for February 12009 at 00h:00. Colour indicates wind speed values ranging between $2 \mathrm{~ms}^{-1}$ and $16 \mathrm{~ms}^{-1}$. rows indicate wind direction

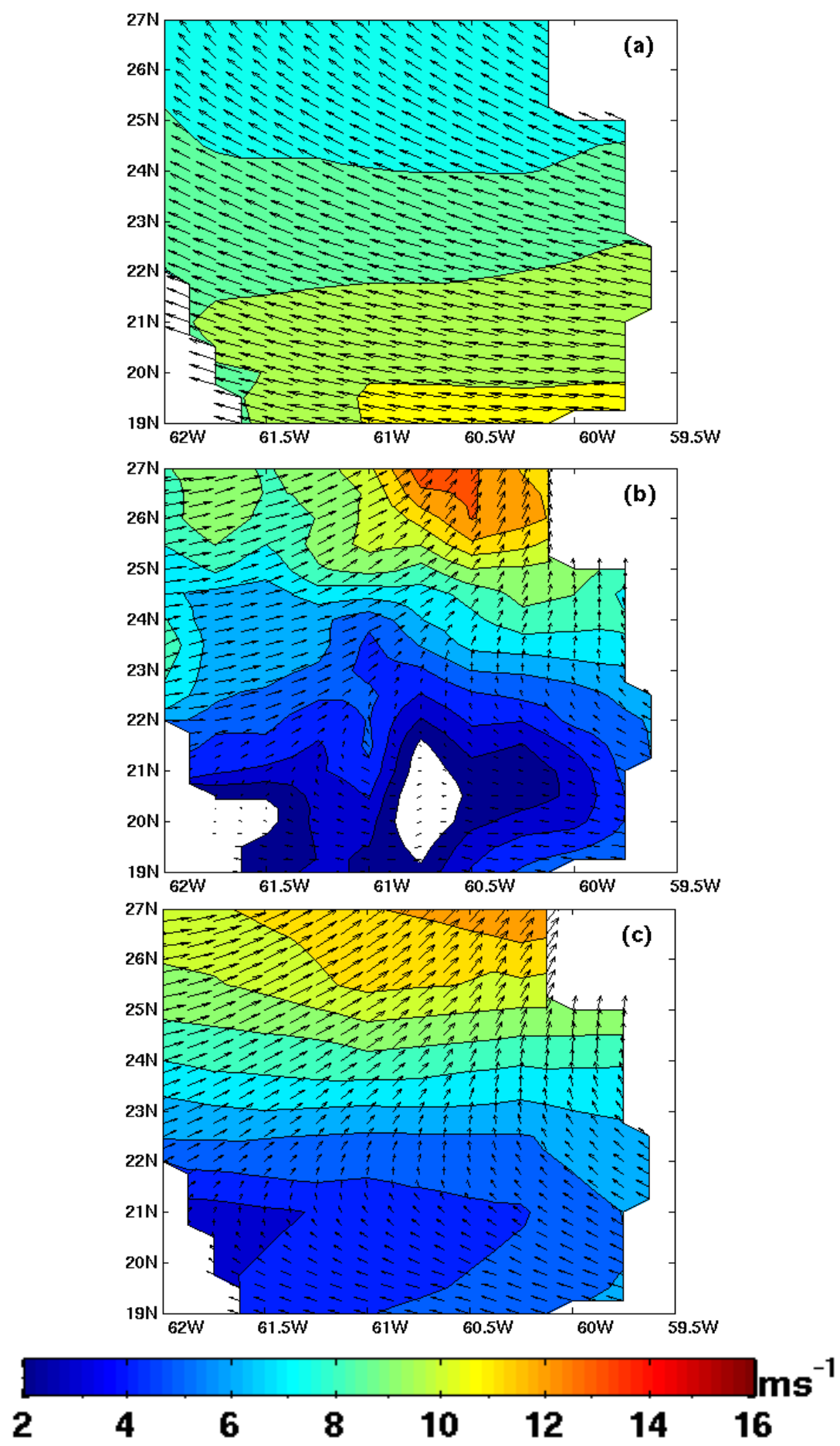


Figure 7 : ASCAT retrievals used for daily-averaged wind field calculation. a) Data occurring between $00 \mathrm{~h}: 00$ and 23h:59mn:59sc of February 1, 2009. b) ASCAT temporal interpolated data added to data shown in a).c) Daily wind field for February 1, 2009
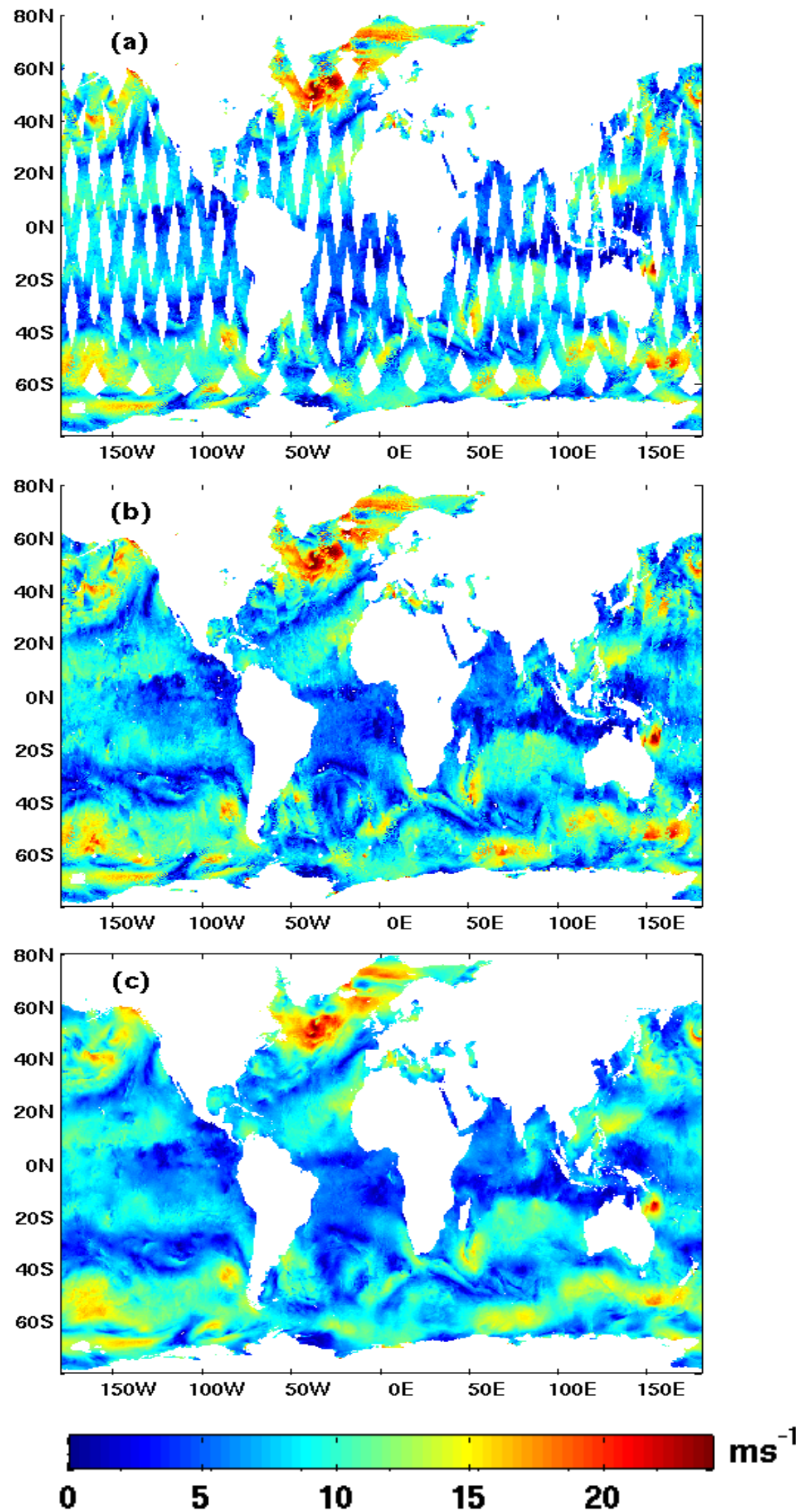
Figure 8: Spatial distributions of the correlation coefficients estimated from ERA Interim and Simulated ASCAT daily zonal (a) and meridional (b) wind components.

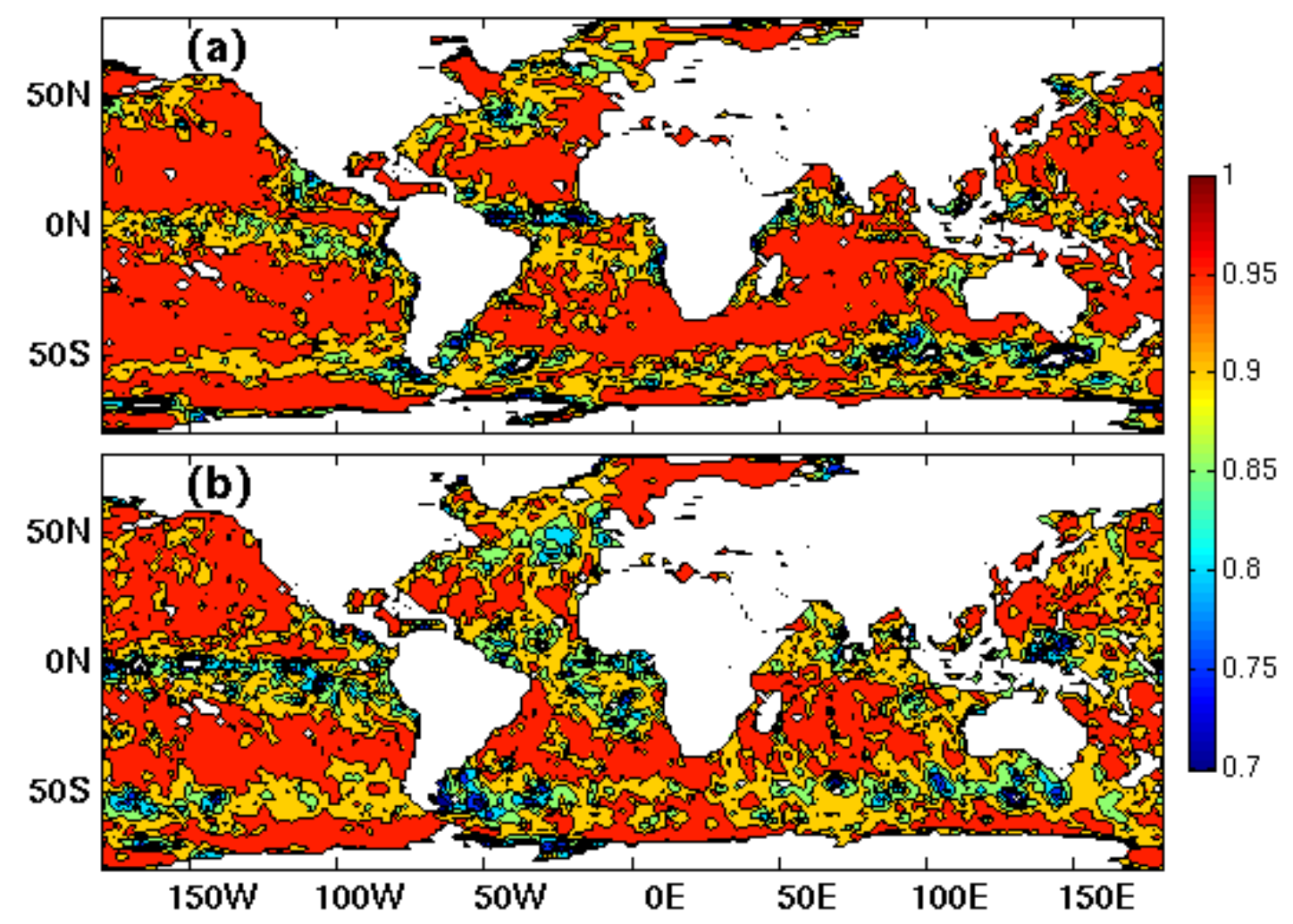

Figure 9: Spatial distribution of Brier Skill Score (BSS) estimated from daily wind speeds during $2008-2009$ period..

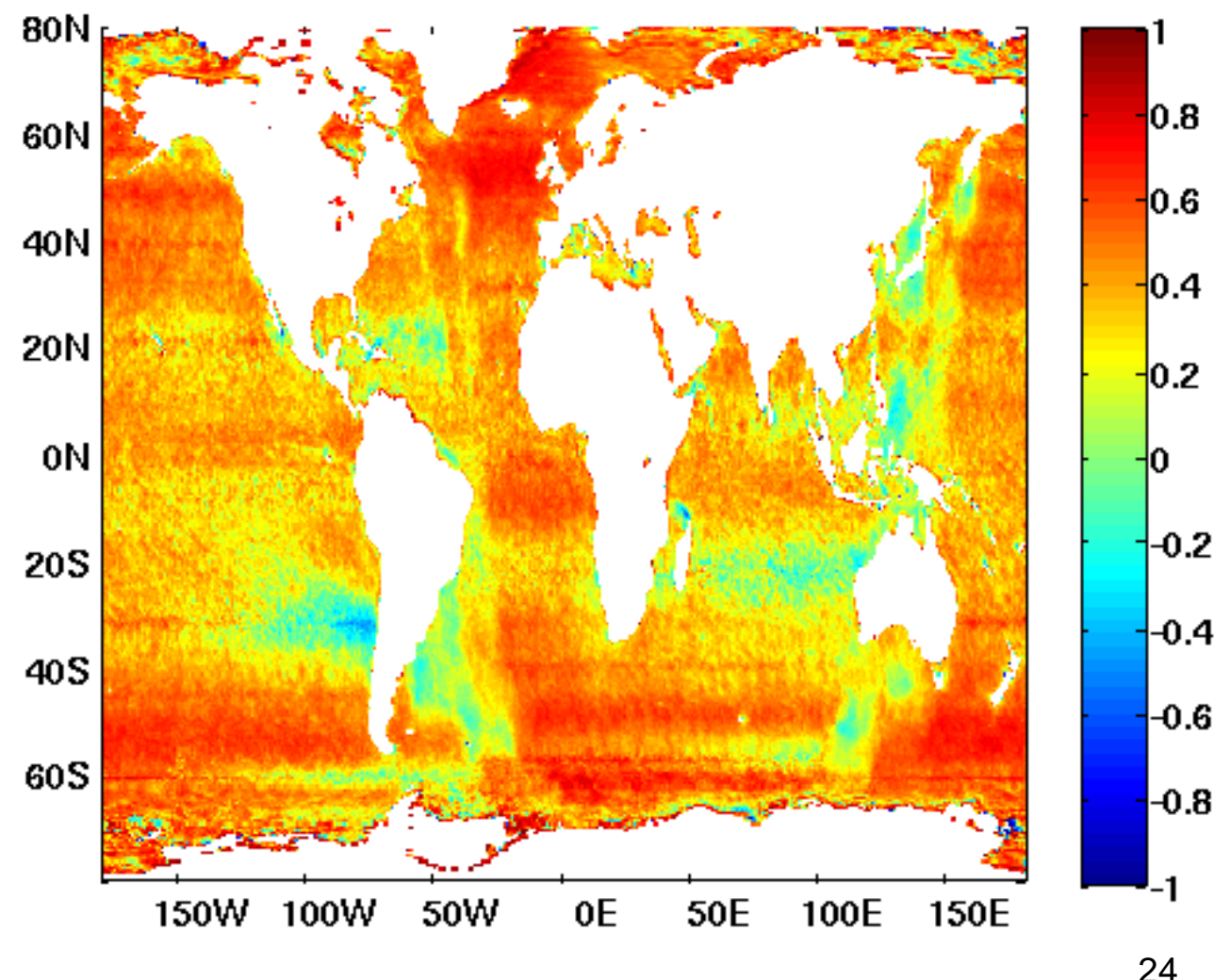


Figure 10: Comparison of daily wind speeds (left column) and wind direction (right column) from DASCAT versus MFUK (first row), NDBC (second row), and TAO, PIRATA, and RAMA (Third row) buoy winds for the period January through December 2009. In wind speed comparisons, inner and outer dashed lines indicate one and two standard deviation values, respectively. The color indicates frequency
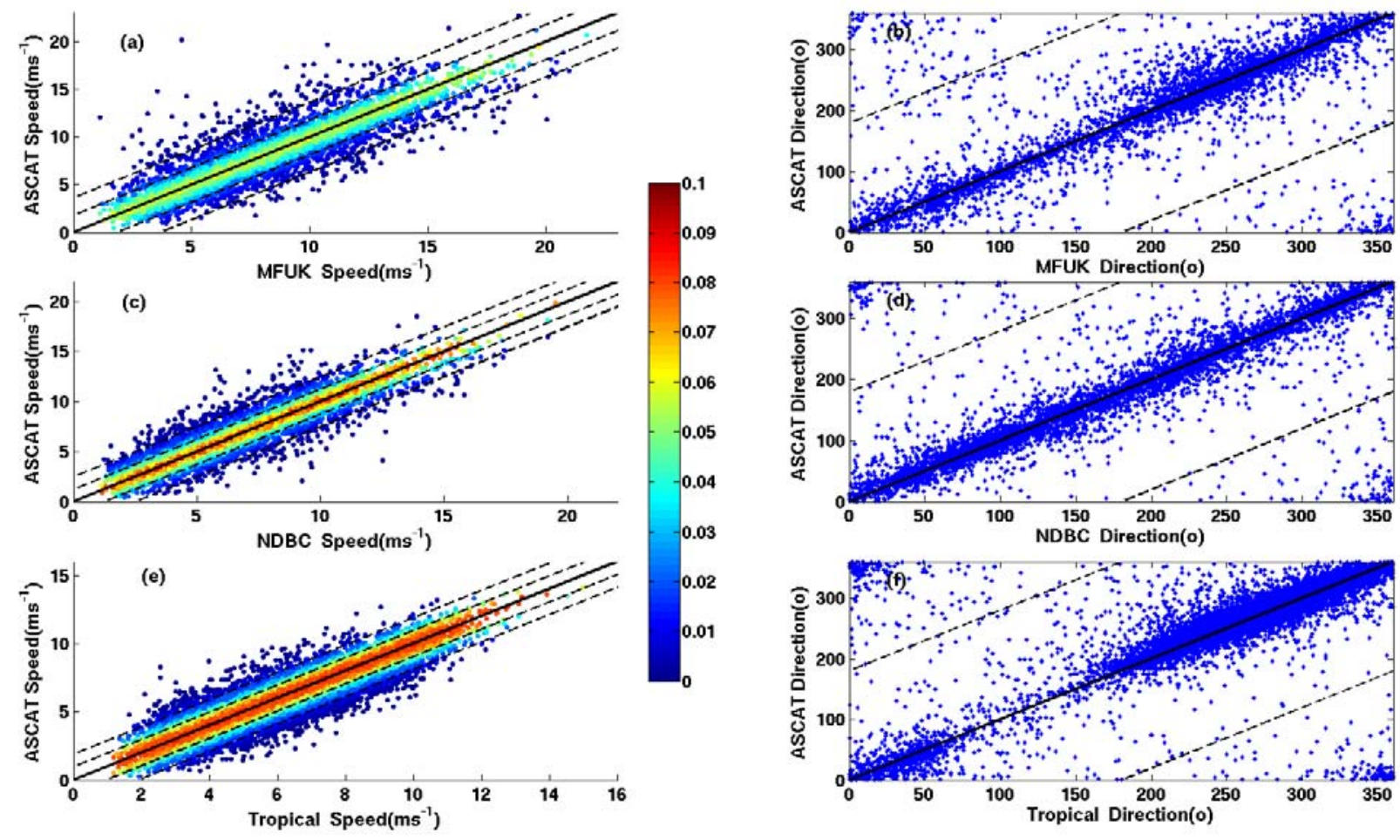

Figure 11 : Rms wind speed difference patterns as a function of buoy wind speed and variability ranges.

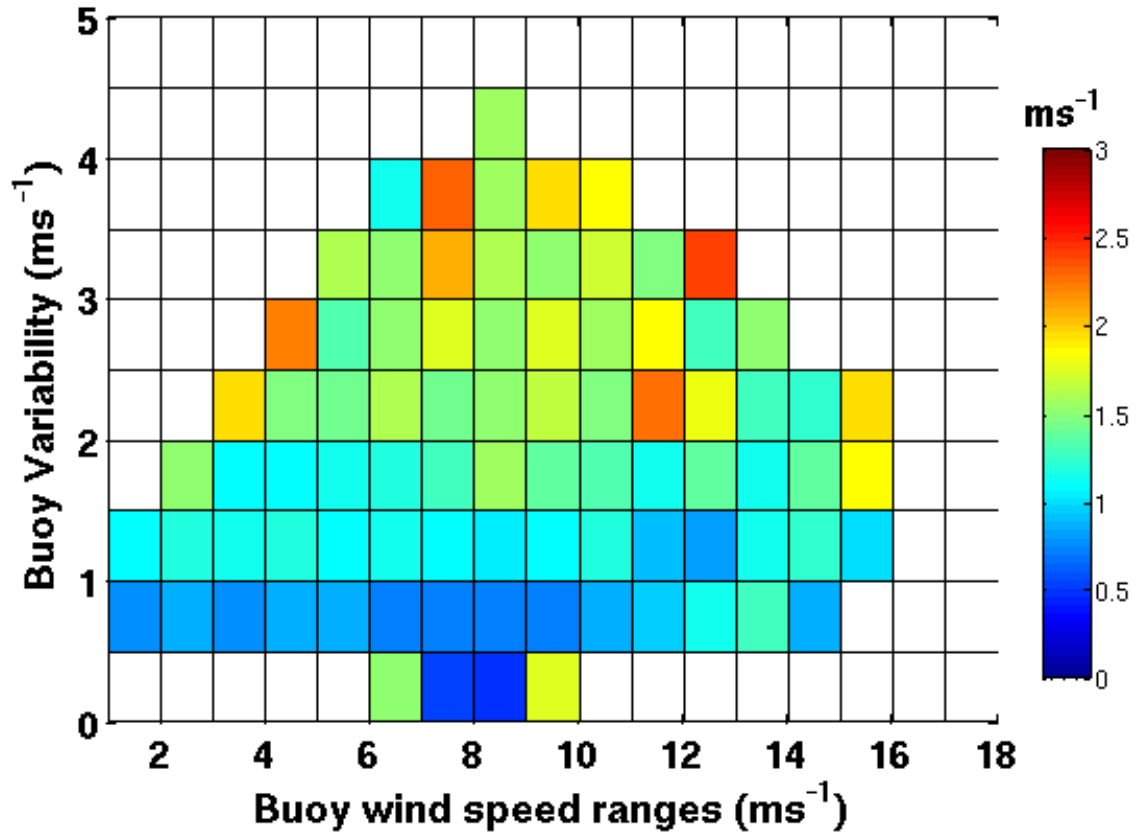


Figure 12: Annual mean wind speeds and directions (a), and the associated wind speed (b), zonal (c), and meridional (d) variability patterns estimated from ASCAT daily data during $2008-2009$ period.

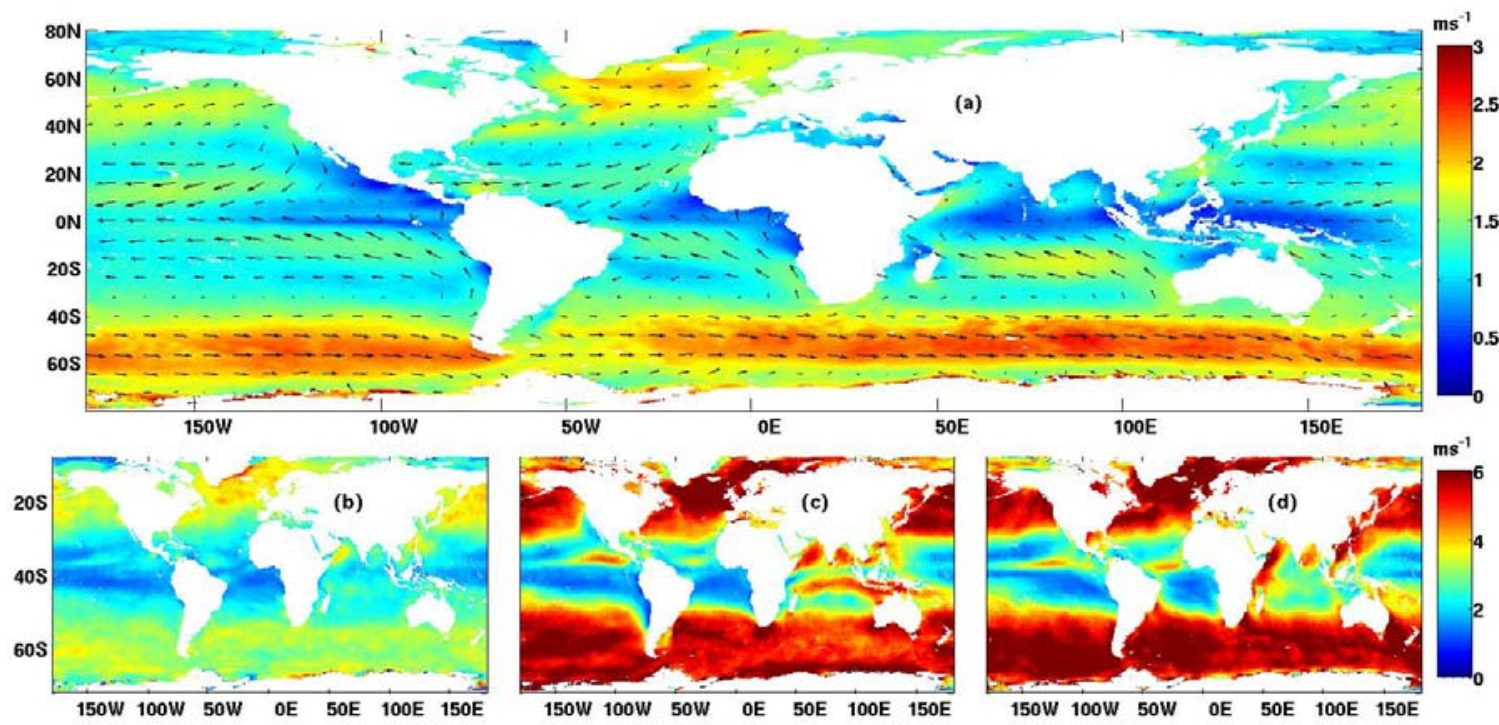

Figure 13: Rms differences between ASCAT and ECMWF ( $1^{\text {st }}$ row), and between ASCAT and ERA Interim ( $2^{\text {nd }}$ row) daily wind speeds ( $1^{\text {st }}$ column), zonal components ( $2^{\text {nd }}$ column), and meridional components ( $3^{\text {rd }}$ column) During $2008-2009$ period.
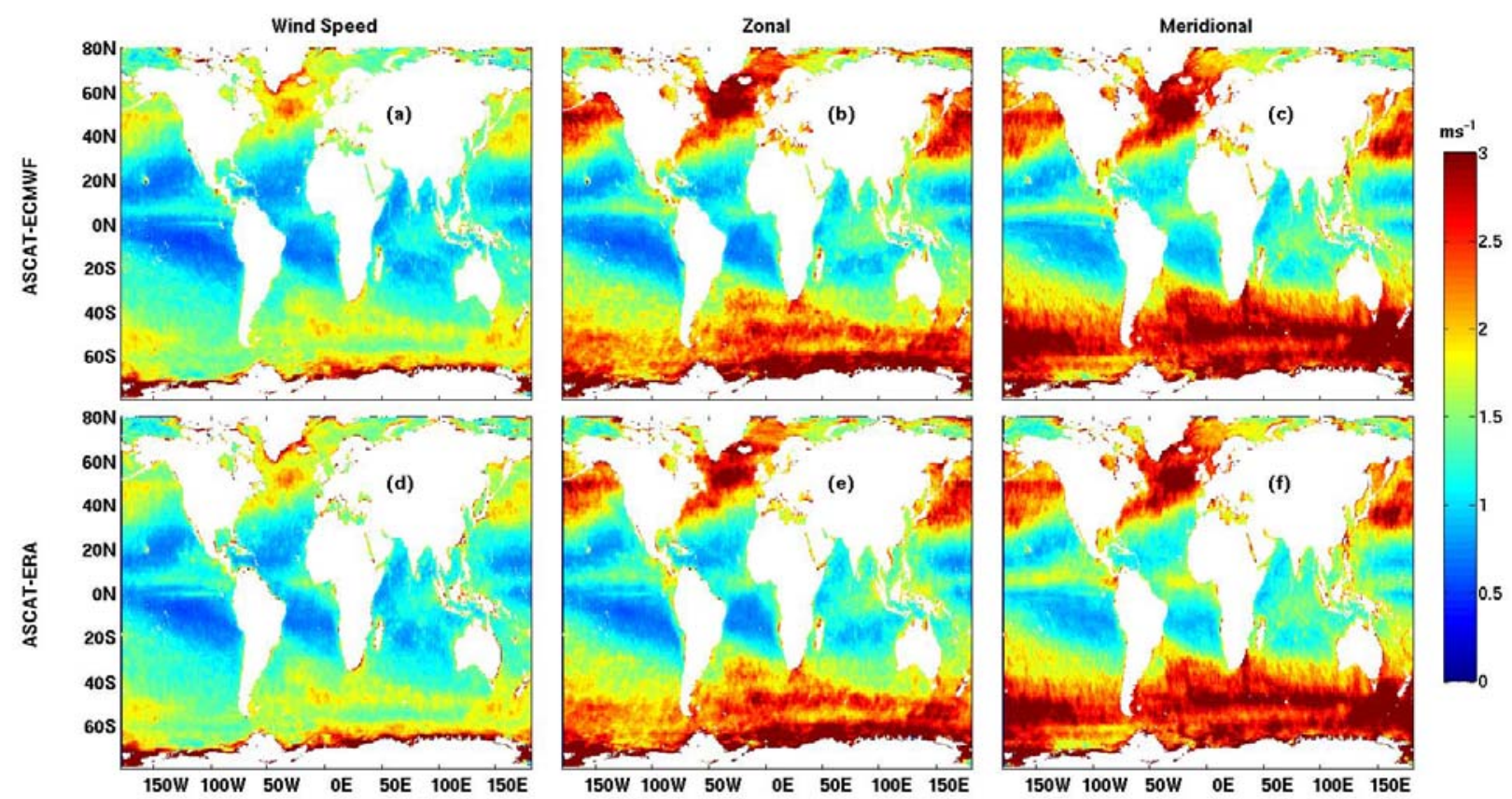
Figure 14: Surface wind speed time series from ASCAT observations (blue dot), ASCAT (red) and ECMWF (black) daily estimates at five oceanic locations: a) $\left(55^{\circ} \mathrm{N}\right.$, $\left.12.6^{\circ} \mathrm{W}\right)$; b) $\left(42.1 \mathrm{~N}, 4.7^{\circ} \mathrm{E}\right)$; c) $\left(0^{\circ} \mathrm{N}, 10^{\circ} \mathrm{W}\right)$; d) $\left(10^{\circ} \mathrm{N}, 55^{\circ} \mathrm{E}\right)$; e) $\left(50^{\circ} \mathrm{S} ; 90^{\circ} \mathrm{E}\right)$

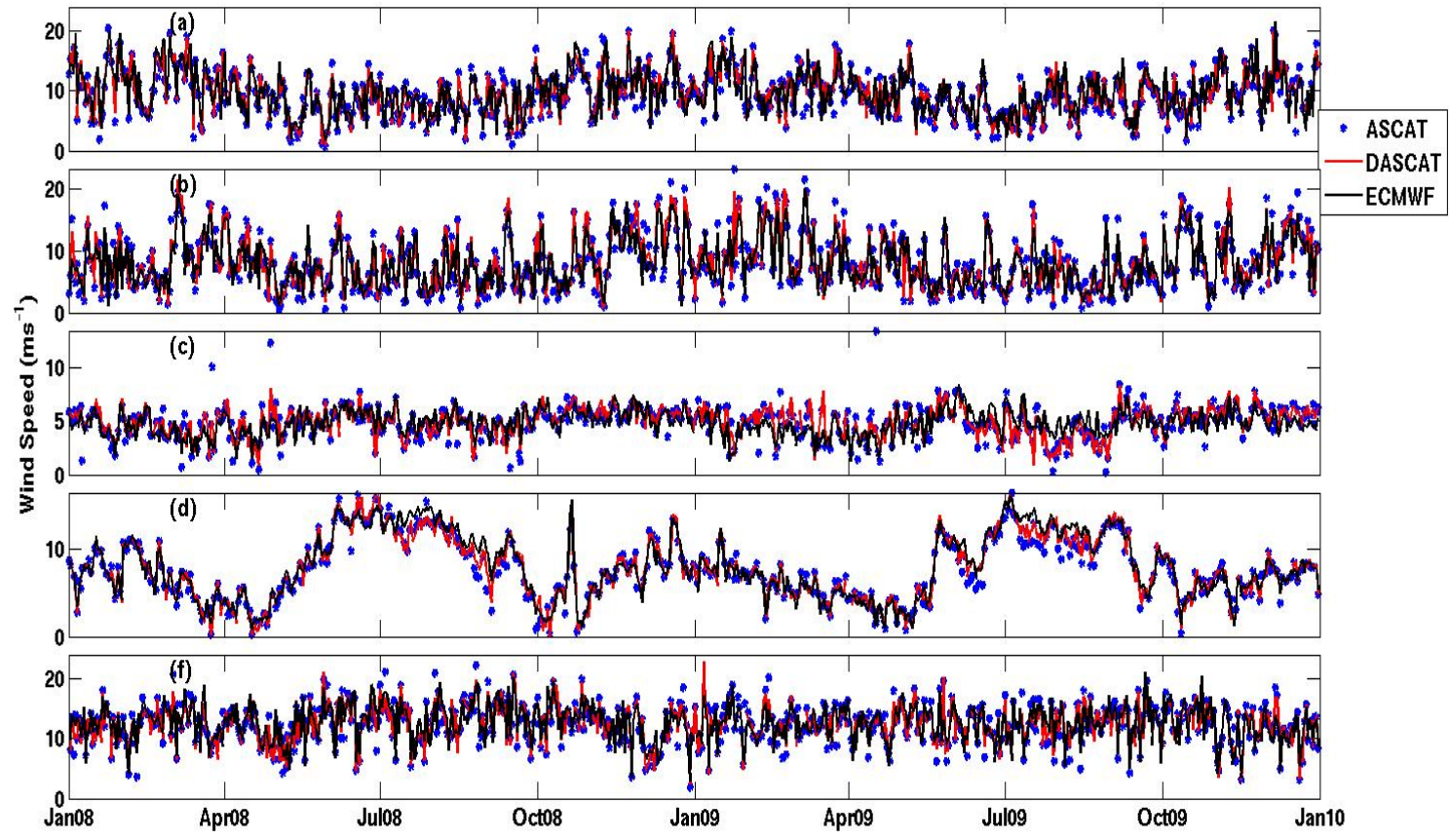

Figure 15 : Comparisons between tropical cyclone collocated wind speed (a and $c$ ) and direction ( $b$ and d) data from ASCAT L2b, DASCAT, and ECMWF during 2008.
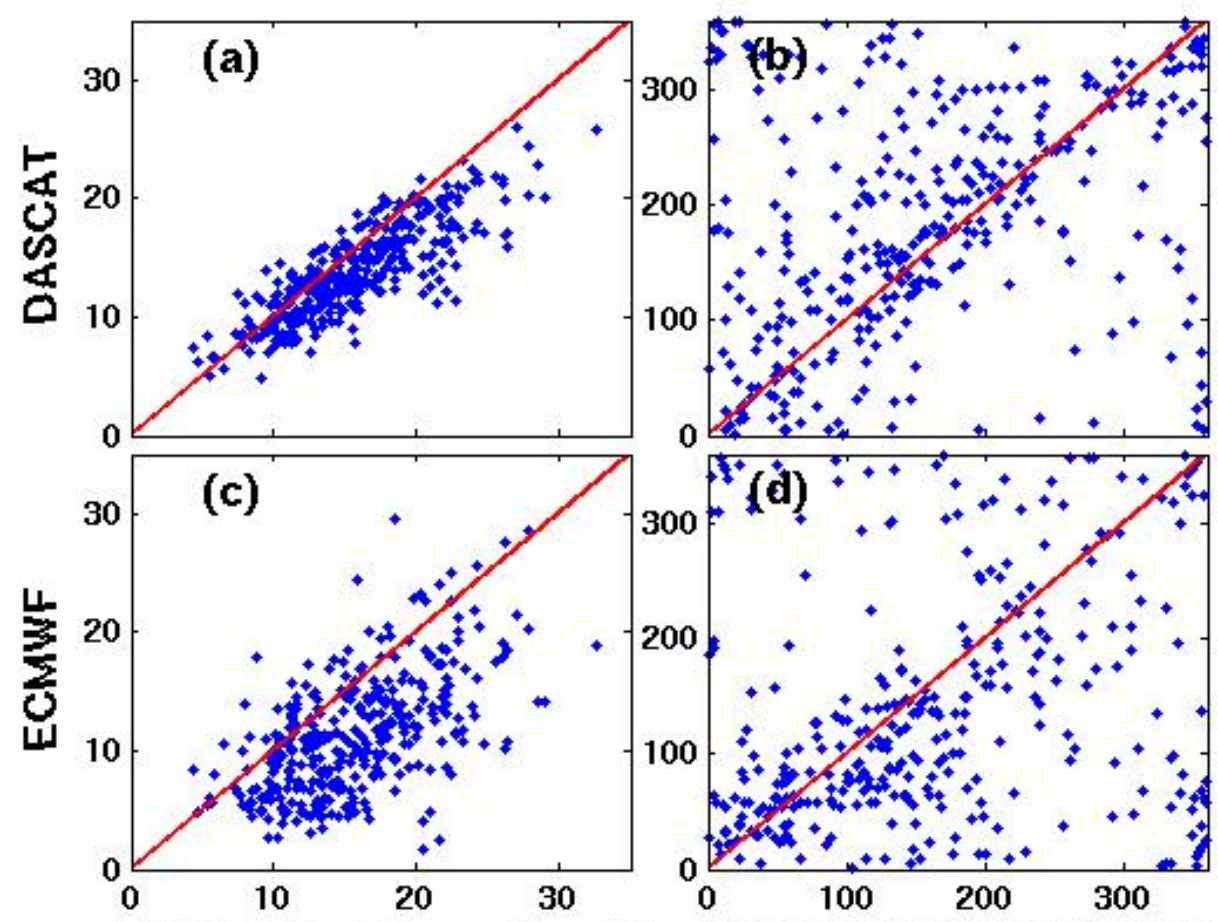

ASCAT Wind Speed $\left(\mathrm{ms}^{-1}\right)$ ASCAT Wind Direction (o) 
Figure 16: Comparisons of wind speeds ( $a$ and $c$ ) and directions ( $b$ and $d$ ) data from ASCAT L2b, DASCAT, and ECMWF for Mistral Events during 2008-2009.

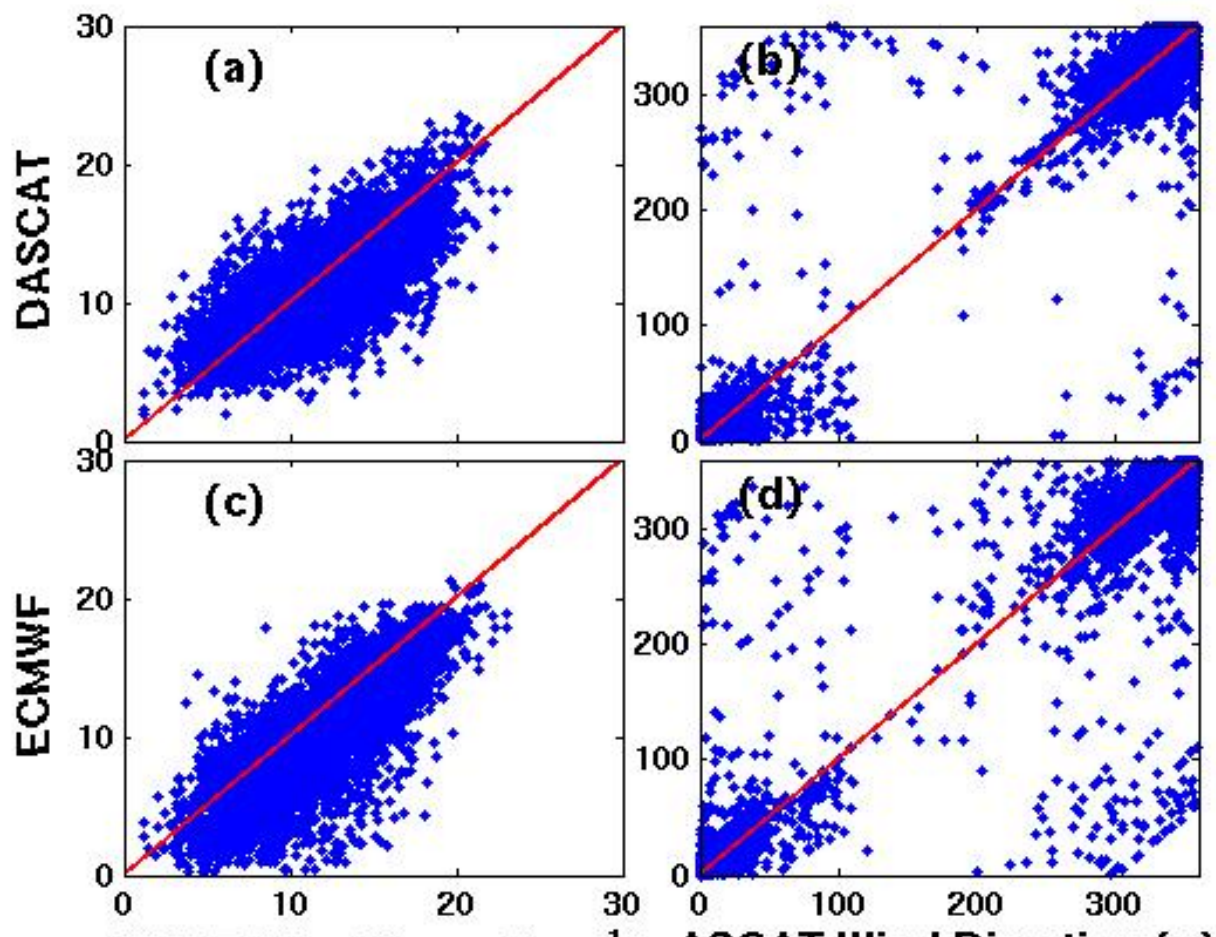

ASCAT Wind Speed ( $\mathrm{ms}^{-1}$ ) ASCAT Wind Direction (o)

Figure 16: Comparisons of wind speeds $(a$ and $c$ ) and directions (b and d) data from ASCAT L2b, DASCAT, and ECMWF for Mistral Events during 2008-2009. 